IZA DP No. 7605

Economic Conditions at Birth, Birth Weight, Ability, and the Causal Path to Cardiovascular Mortality

Gerard J. van den Berg

Bitte Modin

August 2013 


\title{
Economic Conditions at Birth, Birth Weight, Ability, and the Causal Path to Cardiovascular Mortality
}

\author{
Gerard J. van den Berg \\ University of Mannheim, IFAU-Uppsala, \\ VU University Amsterdam and IZA \\ Bitte Modin \\ CHESS, Stockholm University
}

Discussion Paper No. 7605

August 2013

IZA
P.O. Box 7240
53072 Bonn
Germany

Phone: +49-228-3894-0

Fax: +49-228-3894-180

E-mail: iza@iza.org

Any opinions expressed here are those of the author(s) and not those of IZA. Research published in this series may include views on policy, but the institute itself takes no institutional policy positions. The IZA research network is committed to the IZA Guiding Principles of Research Integrity.

The Institute for the Study of Labor (IZA) in Bonn is a local and virtual international research center and a place of communication between science, politics and business. IZA is an independent nonprofit organization supported by Deutsche Post Foundation. The center is associated with the University of Bonn and offers a stimulating research environment through its international network, workshops and conferences, data service, project support, research visits and doctoral program. IZA engages in (i) original and internationally competitive research in all fields of labor economics, (ii) development of policy concepts, and (iii) dissemination of research results and concepts to the interested public.

IZA Discussion Papers often represent preliminary work and are circulated to encourage discussion. Citation of such a paper should account for its provisional character. A revised version may be available directly from the author. 


\section{ABSTRACT}

\section{Economic Conditions at Birth, Birth Weight, Ability, and the Causal Path to Cardiovascular Mortality}

We analyze interaction effects of birth weight and the business cycle at birth on individual cardiovascular (CV) mortality later in life. In addition, we examine to what extent these longrun effects run by way of cognitive ability and education and to what extent those mitigate the long-run effects. We use individual records of Swedish birth cohorts from 1915-1929 covering birth weight, family characteristics, school grades, sibling identifiers, and outcomes later in life including the death cause. The birth weight distribution does not vary over the business cycle. The association between birth weight (across the full range) and CV mortality rate later in life is significantly stronger if the individual is born in a recession. This is not explained by differential fertility by social class over the cycle. Ability itself, as measured at age 10, varies with birth weight and the cycle at birth. But the long-run effects of early-life conditions appear to mostly reflect direct biological mechanisms. We do not find evidence of indirect pathways through ability or education, and the long-run effects are not mitigated by education.

JEL Classification: $\quad \mathrm{I10}, \mathrm{I12}, \mathrm{I21}, \mathrm{I31}, \mathrm{J} 10, \mathrm{~J} 13, \mathrm{~N} 34, \mathrm{C} 41, \mathrm{E} 32$

Keywords: longevity, genetic determinants, health, business cycle, life expectancy, cardiovascular disease, school grades, siblings, fetal programming, cause of death, life course, developmental origins, nature and nurture, cognitive ability, education, stratified partial likelihood, recession

Corresponding author:

Gerard J. van den Berg

Department of Economics

University of Mannheim

L7, 3-5

68131 Mannheim

Germany

E-mail: gjvdberg@xs4all.nl

\footnotetext{
"We thank Denny Vågerö, Janet Currie, Eric Bonsang, Olle Lundberg, llona Koupil, Frank Windmeijer, Bert van Landeghem, Jerome Adda, and participants at seminars at Zürich, EUI Florence, Bristol, Cologne, Stockholm and Rostock, Keynote Lectures at conferences on Labor and Demographic Change (Berlin) and Health and Human Capital (Mannheim) and at ADRES (Strasbourg), and conferences in Bonn, Lund, Mannheim, Nürnberg, Maastricht, and München, for helpful comments. We are grateful to CHESS and its PI llona Koupil for permission to use the UBCoS Multigen data.
} 


\section{Introduction}

Recently, the interest in long-run effects of early-life conditions has been strongly increasing. It has been shown that a range of diseases at high ages have "developmental origins", i.e. can be caused by deprivation in utero and around birth. This applies in particular to cardiovascular (CV) morbidity and mortality as outcomes. Concerning the conditions in utero, a large part of the empirical literature has focused on birth weight as an indicator of those conditions. Surveys and metastudies of the epidemiological and medical evidence of associations of birth weight indicators and CV morbidity and mortality later in life have been published in Poulter et al. (1999), Rasmussen (2001), Lawlor, Ben-Shlomo and Leon (2004), and Huxley et al. (2007). The survey in Eriksson (2007) also focuses on medical indicators measured shortly after birth. See e.g. Gluckman, Hanson and Pinal (2005) and Barker (2007) for overviews of the underlying bio-medical mechanisms. At the same time, social scientists and demographers have become interested in the importance of parental income and socio-economic status around birth as explanations for health later in life (Almond and Currie, 2011). An increasing number of studies captures early-life conditions through transitory changes in exogenous contextual variables. Examples are the season of birth (Doblhammer, 2004), the business cycle at birth (Van den Berg, Lindeboom and Portrait, 2006, Van den Berg, Doblhammer and Christensen, 2011), deviations of food prices around birth (Bengtsson and Lindström, 2000, 2003), and the occurrence of extreme events like epidemics, wars, and famines around birth (see Lumey, Stein and Susser, 2011, for an overview of famine studies). Transitory changes in contextual or macro-economic conditions during pregnancy of the mother and early childhood are unanticipated and exogenous from the individual point of view, and they affect income for many households. For example, in a recession, the provision of sufficient nutrients and good living conditions for infants and pregnant women may be hampered, and the stress level in the household may be higher than otherwise. It can be argued that the only way in which the indicators can plausibly affect high-age health is by way of the individual early-life conditions.

In this paper we aim to combine epidemiologic and social science research on long-run effects of early-life conditions, by way of a joint analysis of the effects of birth weight and the business cycle at birth as well as their interaction effects. We are the first study to do so. This allows us to address whether the relation between birth weight and a high risk of CV mortality is stronger if the individual was born in a recession. Clearly, this requires data of cohorts of individuals with a sufficiently high number of observed deaths (i.e., cohorts born many decades ago), 
followed over time from birth to death, for whom birth weight was recorded as well. For this purpose we use the Uppsala Birth Cohort Study (UBCoS) which is a lifelong follow-up study of individuals born in 1915-1929 and which is probably the only data set in the world meeting our requirements. The data set contains information registered at birth, including socio-economic household characteristics, as well as more recent information from censuses and various administrative registers, up to the present day.

The results can be used to identify markers of early-life conditions that are associated with high-age CV mortality, which may be useful for health policy. However, we aim to go beyond this and provide a causal explanation of the results. This is the second aim of the paper. We perform a range of additional analyses to shed light on the underlying mechanisms.

A complication for any causal explanation is that birth weight is not an exogenous causal determinant of health later in life but rather an intermediate outcome between conditions in utero and events later in life, where the conditions in utero are partly shaped by genetic and family background characteristics. This has been acknowledged in the medical and epidemiological literature (see arguments made in e.g. the surveys of Poulter et al., 1999, Rasmussen, 2001, Huxley et al., 2007, Lawlor, 2008, Basso, 2008, and also in Ben-Shlomo, 2001, and Järvelin et al., 2004). With shared unobserved determinants of birth weight and the health outcome, an association between birth weight and health later in life does not imply the presence of a causal effect of early-life conditions.

We investigate this issue by examining whether the birth weight distribution varies over the business cycle. Such an association reveals whether economic conditions during pregnancy causally affect birth weight or whether birth weight is primarily driven by genetic and family background characteristics. Clearly, the analysis is susceptible to selectivity of newborns across the business cycle at birth. If babies with low birth weight born in a recession die more often shortly before or during birth than if birth takes place in a boom, then a crude comparison between mean birth weight in booms and recessions underestimates the causal effect of economic conditions during pregnancy on birth weight. We therefore examine whether the left-hand tail of the birth weight distribution is particularly sensitive to the business cycle.

Moreover, we examine whether the birth rate and the composition of newborns vary with the business cycle, where the composition is captured by the social class of the household as derived from the parents' occupation. In addition to this, we pursue an alternative approach by comparing outcomes across siblings, using Stratified Partial Likelihood. This approach is the equivalent of fixed-effect panel 
data estimation in linear models. By using only within-household variation to study long-run effects, we control for birth planning behavior that is tuned to the business cycle. The issue whether newborns who were exposed to different transitory contextual conditions are systematically different in a selective way has haunted the empirical literature on long-run effects (see e.g. Brown, 2011), and our paper is the first to use a fixed-effect estimation method to control for selectivity of births at the household level when studying mortality outcomes. ${ }^{1}$ Our paper thus provides a methodological innovation to the literature.

To enhance our understanding of the pathway from early-life conditions to CV mortality later in life, we take cognitive ability into account. It is known that birth weight in the normal range is positively associated with IQ (see e.g. Matte et al., 2001, Richards et al., 2001, and Shenkin, Starr and Deary, 2004), and it has also been shown that cognitive ability is associated with late-life health (see Hart et al., 2004, and Batty, Deary and Gottfredson, 2007). Of course, these are two separate results, and by themselves they do not imply that long-run effects predominantly run through ability. In fact, studies have speculated about an alternative role for ability. Specifically, high-ability individuals may be able to mitigate negative long-run effects of adverse conditions at birth since they may be better able to apply knowledge on what constitutes a healthy lifestyle, and since they may invest more in health because their return to health investments may be higher (see e.g. the overviews in Batty, Deary and Gottfredson, 2007, and Van den Berg and Lindeboom, 2007). Our data contain observations of individual school grades per subject at age 10. We use these as indicators of cognitive ability. We analyze how they depend on the business cycle at birth and birth weight and their interaction. Next, we re-estimate the CV mortality models, including ability and its interaction with birth weight and the business cycle indicator at birth as explanatory variables. We are the first to perform such analyses. Together, the results are informative on whether the over-all effect of (certain) early-life conditions on CV mortality is driven by a causal pathway running through ability. In addition, they reveal whether ability mitigates adverse conditions around birth. As a by-product, they reveal whether conventional ability measures are exogenous explanatory variables for outcomes later in life or whether they are mitigated by early-life conditions that affect both ability and the outcomes later in life.

We essentially replicate the analysis described in the previous paragraph with the realized level of education, taking into account that it may depend on cogni-

\footnotetext{
${ }^{1}$ Van den Berg et al. (2010) use siblings data of immigrant families but consider adult height as the outcome. Van den Berg, Doblhammer and Christensen (2011) use twin data to study long-run CV mortality effects, but obviously twins face identical contextual conditions at birth.
} 
tive ability. Taken together, this enables us to assess the extent to which ability and education intervene in the biological long-run effects of early-life conditions. This goes some way towards an assessment whether the long-run effects are driven by direct biological mechanisms or by indirect pathways that may be affected by individual decisions. We should note from the outset that from an econometric point of view, these analyses suffers from a lack of instrumental variation in the level of education.

The UBCoS data have been used by a number of studies, some of which focus on particular aspects of the analysis in this paper. Since our analysis focuses on men, we summarize some findings for men in these studies. Leon et al. (1998) is a landmark study of the aetiological importance of measures of in utero conditions (like birth weight) on later-life risk of mortality due to ischaemic heart disease. It finds a significant association for men. The article also emphasizes the quality of the data as compared to other studies using historical birth weight observations. Rajaleid, Manor and Koupil (2008) find that birth weight and social class at birth do not have interaction effects on mortality due to ischaemic heart disease. Goodman, Gisselmann and Koupil (2010) find that birth weight positively affects ability as captured by the mean school grade. Many other studies use different data to estimate associations between two or more of the variables we consider. We refer to the discussion of the estimation results below for references to studies with other data that are of particular relevance for our study.

Concerning the birth weight variable we should emphasize that we examine this variable across the population of newborns, so most values are in the normal range. This is in line with much of the epidemiological literature on birth weight but contrasts to the economic literature which focuses on "low birth weight" (i.e., below $2.5 \mathrm{~kg}$ ). The latter is important from a public health point of view but is not a common outcome (see e.g. Almond, Chay and Lee, 2005). With our modestly sized sample we are not in a position to reliably estimate effects on (or of) the occurrence of low birth weight.

The paper is organized as follows. Section 2 presents the data and discusses variables that we use in the analyses. Section 3 examines the birth weight distribution over the business cycle. Section 4 describes the formal empirical analyses and gives the key results for the relation between our early-life indicators and cardiovascular mortality later in life. Section 5 takes ability and education into account. Section 6 concludes. 


\section{The data}

\subsection{Individual records from the UBCoS data}

Our individual data records are derived from the Uppsala Birth Cohort Study, which is a lifelong follow-up study of representative birth cohorts of all men and women born in Uppsala in 1915-1929. ${ }^{2}$ Information on social and earlylife characteristics of the original birth cohorts and their parents was collected from the register of the (academic) hospital in Uppsala. A range of social and health variables for these individuals has been extracted from censuses (starting with the 1960 census), routine administrative registers (starting in 1961 or later), and archives. This includes school archives and the death cause register. The individuals are followed over time up to the end of 2002, so that the highest observed death age is 87 . We refer to the UBCoS studies listed in Section 1 for detailed descriptions of the data set and the way it has been assembled.

In the paper we restrict attention to male individuals (sample size 7634). This is because the literature on the effects of early-life conditions on CV morbidity and mortality has found the strongest effects on men. ${ }^{3}$ We omit the 139 individuals whose lifetime duration is right-censored at birth (implying that we do not observe anything about them after birth), because these do not contribute to the estimation of mortality effects. This results in a sample size of 7495 . Not all variables are observed for all of these individuals, although birth date, lifetime duration (if completed) and birth weight are observed for virtually every individual. To maintain reasonable sample sizes, we use the largest possible sample for each analysis separately.

The birth and death dates and the resulting individual lifetime durations are observed in days. The data do not contain observations of the death cause prior to $1952 .{ }^{4}$ Our mortality analyses therefore condition on survival until 1952, implying that the lowest possible observed death age is 22 . This is not a serious restriction, as (i) we are not interested in short-run mortality effects of early-life

\footnotetext{
${ }^{2}$ Rajaleid, Manor and Koupil (2008) even demonstrate that it is representative of Sweden, for the birth years 1915-1929.

${ }^{3}$ See e.g. the surveys mentioned in Section 1. See Low (2001) and Eriksson et al. (2010) for a biological explanation of these findings. An additional reason to restrict attention to men concerns the fact that higher education was hard to enter for women born early in our observation window; see Subsection 2.2.

${ }^{4}$ The cause-of-death register containing personal numbers runs from 1961 onwards. Researchers in Uppsala have manually coded death causes before 1961. This study is the first to use death causes for deaths in 1952-1960, but these additional observations do not influence the results.
} 
conditions on infant or child mortality, and (ii) CV diseases are not a major cause of deaths before age $22 .{ }^{5}$ The restriction leads to a sample size of 6324 men who are known to be alive in 1952. For six of these, birth weight is not observed. The death cause is classified according to the ICD system, revisions 6 to 10, at the 3 to 4-digit level. CV mortality concerns death due to cardiovascular malfunctions and diseases, including ischaemic (or coronary) heart disease and cerebrovascular accidents (strokes). Among the individuals known to be alive in 1952, 23\% are observed to die from CV-related causes. Furthermore, $29 \%$ are observed to die from other causes, and $48 \%$ have right-censored lifetime durations (almost all of these are still alive at the end of 2002). Table 1 gives some sample statistics of the main variables that were made accessible for our study.

Birth weight was recorded in grams. Notice from Table 1 that the mean birth weight is of the same order of magnitude as is it nowadays. In Subsection 3.2 we consider the variation of the birth weight distribution over the business cycle. The socio-economic status or social class at birth is a grouped hierarchically ordered version of the Swedish SEI code which in turn is based on the occupation of the main breadwinner in the household. The values run from 1 (highest class) to $7 .{ }^{6}$

We capture cognitive ability by the spring-term "grade" (or "mark" or "score") in the spring semester of the 3rd grade school year, which was typically at age 10 . Virtually all children attended a public elementary school at that age (in the next subsection we discuss historical school reforms in Sweden). The grades are coded into numerical values according to a method devised by the Swedish Ministry of Education. We primarily use the grade in arithmetic and geometry. The resulting values range from 0 (worst) to 18 (best), although the values 16-18 are not observed. In addition, we use the individual average grade across all subject fields. We only use school archive information for individuals who attended schools in the Uppsala school district. This surrounds and includes the city of Uppsala and is somewhat smaller than the area covering the residences of the UBCoS sample members at birth (see Subsection 2.3). Restricting school data to the district is motivated by the fact that within it, the test used to determine the grades/scores as well as the logistical and pedagogical setting are homogeneous across schools and hence across individuals. However, the results do not change substantially if we use school grades for all individuals for whom these were digitized (5389 individuals).

\footnotetext{
${ }^{5}$ However, infant mortality may lead to selectivity of survivors. We return to this in Section 3 .

${ }^{6}$ The category where the occupation is unknown is assigned the value 7 because in virtually every respect its outcomes are less favorable than those of other classes.
} 
Table 1: Summary statistics of the UBCoS sample

\begin{tabular}{|c|c|c|c|c|}
\hline variable & \# cases & $\begin{array}{l}10^{t h} \\
\text { percentile }\end{array}$ & $\begin{array}{l}\text { mean } \\
\text { or } \% \text { of total }\end{array}$ & $\begin{array}{l}90^{t h} \\
\text { perc. }\end{array}$ \\
\hline \multicolumn{5}{|l|}{ lifetime spells: } \\
\hline $\begin{array}{l}\text { observed death date if observed to } \\
\text { survive until Jan. } 1,1952\end{array}$ & 6324 & & $52 \%$ (i.e. 3305 ) & \\
\hline death cause if uncensored spell: & & & & \\
\hline CV mortality & 3305 & & $44 \%$ (i.e. 1465 ) & \\
\hline other cause & 3305 & & $56 \%$ (i.e. 1840 ) & \\
\hline \multicolumn{5}{|l|}{ other variables: } \\
\hline birth weight (grams) & 7192 & 2800 & 3475 & 4150 \\
\hline birth year & 7199 & 1916 & 1922.6 & 1928 \\
\hline social class at birth ( 1 to 7 : high to low) & 7199 & 2 & 4.2 & 6 \\
\hline birth in city & 7199 & & $41 \%$ & \\
\hline mother's age, at birth & 7195 & 21 & 28.4 & 38 \\
\hline mother married, at birth & 7199 & & $80 \%$ & \\
\hline cognitive ability (mark 1 to 15 : low to high) & 4380 & 5 & 7.15 & 9 \\
\hline$\geq 1$ brother in sample & 7199 & & $30 \%$ (i.e. 2167 ) & \\
\hline education level ( 1 to 6 : low to high) & 5842 & 1 & 1.8 & 4 \\
\hline
\end{tabular}

The highest individual level of education is taken from the 1970 census which is the most recent version available to us. Consequently, it is only observed if the individual survives until 1970. In a sensitivity analysis we also use the 1960 value.

\subsection{Macro-economic business-cycle data}

As mentioned in the introduction, we use the business cycle as an indicator of economic conditions early in life. Ideally, one would like to intervene in the life of individuals around their birth date and randomly manipulate the economic conditions of their care-takers for certain short periods around birth. In practice, we do not observe the economic conditions of the household around the 
birth date of individuals who are currently old. Moreover, even if observations of those conditions were available, it would not be possible to draw causal inference from the association between those conditions and late-life outcomes, because the former are not exogenous. Specifically, these conditions and outcomes may all be influenced by unobserved family-specific background characteristics such as family wealth, cultural habits, and genes. Contextual variables do not have this disadvantage, because they are not household-specific and cannot be influenced by the household (although, as we discuss below, individuals may be exposed in different degrees, because of decisions by ancestors). A contextual variable should affect economic conditions in the household at birth. In that case, the contextual variable is an indicator of early-life economic conditions.

The national annual per-capita gross domestic product (GDP) in constant prices is an example of such a contextual variable. However, the GDP level is less useful for our purposes than the deviation of GDP around its trend value. To see this, compare an individual born in an era with a high GDP level to an otherwise identical individual born in an era with low GDP. A prolonged era with a high GDP leads to innovation and investment in hygiene and health care, which decreases mortality later in life for those born in this era. These are secular improvements in life conditions over time, and they make GDP comparisons uninformative on effects of individual early life conditions. A related practical complication is that GDP displays a strong positive trend over time. A high GDP level at birth implies a high GDP level throughout life. An empirical analysis that tries to take this into account by allowing a mortality rate at a given age to depend on current and past GDP levels leads to estimates that are potentially very sensitive to small model misspecifications. For example, if the postulated relation is log-linear in the mortality rate and current GDP, and the true relation is slightly different, then this may show up as a significant effect of GDP earlier in life. Short-term cyclical movements in GDP do not give rise to major secular improvements. Thus, one obtains evidence of a causal long-run effect by relating an outcome later in life to the state of the business cycle early in life, across a range of birth cohorts.

The data on annual real per-capita GDP are from Edvinsson (2005). ${ }^{7}$ This time series is virtually identical to the corresponding series in Mitchell (2003). We perform a trend/cycle decomposition of log annual real per-capita GDP using the Hodrick-Prescott (HP) filter. We use smoothing parameter 500. The values of the cyclical terms are robust with respect to the smoothing parameter, and so are

\footnotetext{
${ }^{7}$ The time series used in this paper, including descriptions of their origin and/or construction, are available upon request.
} 
the resulting intervals within which the terms are positive or negative. Indeed, transitory macro-economic conditions are readily observable (see Figure 1 for the cycle and trend as functions of calendar time).

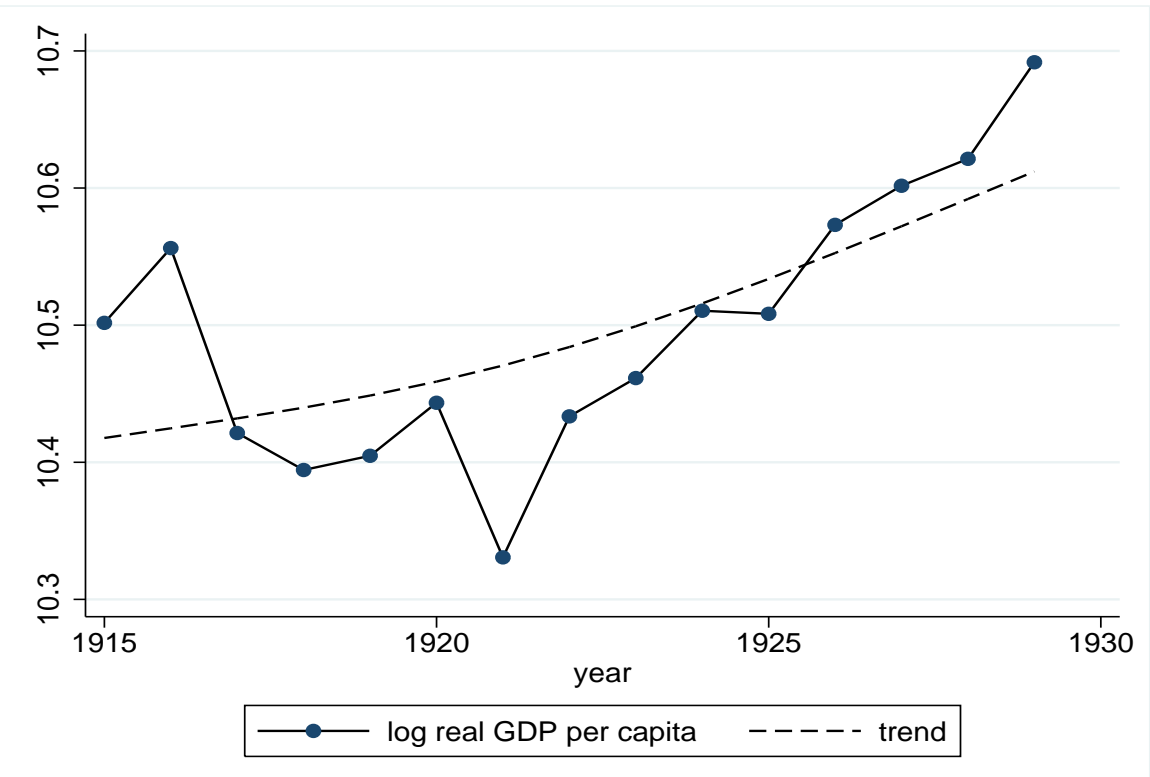

Figure 1. log real GDP per capita: trend and cycle

Clearly, there is a substantial amount of cyclical variation. Like in other European countries, the economy was in a slump just before the end of World War I (in which Sweden did not participate), with international trade having come to a standstill and inflation soaring. The 1918 influenza epidemic exacerbated these problems. There was another severe recession in 1921. Shortly before 1930, the economy was booming. The Great Depression entered Sweden towards the end of 1931, which is beyond the interval of our birth cohort years. This depression was not as severe as in many other countries, and in 1932 a strong recovery set in which subsequently developed into a prolonged boom (Jonung and Hagberg, 2005a).

The business cycle pattern in Figure 1 corresponds closely to descriptions given in the contemporaneous literature, e.g. Thorp and Thorp (1926). A number of recent studies discuss GDP and business cycle fluctuations in our data window (Jonung and Hagberg, 2005b, Grytten, 2006, Lobell, Schön and Krantz, 2007, and some references in those studies). Jonung and Hagberg (2005b) demonstrate that the depression of 1921 was similar in depth to recent depressions but that its duration was much shorter. 
One may wonder whether unemployment data exist providing cyclical indicators that are more informative on workers' conditions than GDP fluctuations. However, in the absence of a comprehensive unemployment insurance (UI) system until 1935, there was no systematic collection of comprehensive unemployment figures. In fact, two different types of income support for individuals without work have led to counts of what could be called "types of unemployment". In case of trade union membership, laid-off individuals could receive support funding from the union. Hence, the unions kept track of the monthly number of unemployed members. Socialstyrelsen (1915-1929) provide these numbers as well as the total number of members. A major problem with the use of this series is that the trade unions only covered a small subset of the labor force, and this subset changed markedly over time during our birth cohort years (see also Grytten, 2006). The attractiveness of union membership depended on the extent to which support funding was available. In addition, the data were only collected by a subset of unions and local union charters, covering on average only about $8 \%$ of the labor force, where again the subset changed over time. Moreover, sector-specific unions did not use uniform criteria to define unemployment (e.g. with respect to the minimum number of days out of work).

A second type of unemployment indicator was collected by the local public employment offices in connection to their efforts to (i) match unemployed workers to vacancies, and (ii) assign unemployed workers to subsidized public work (notably road building). The latter entailed income support. For our objectives, the indicators based on numbers of job seekers at the public employment offices also suffer from a number of disadvantages. According to Socialstyrelsen (1915-1929), the incentive to report oneself as unemployed at the public employment office depended on the extent to which vacancies or public work opportunities were available. The latter fluctuated considerably over time. The size and number of local public offices changed substantially during our observation window, affecting the costs of travel to the nearest public office. Matching was also carried out by private employment agencies. The number of job seekers at the public employment offices as a fraction of the labor force was known to severely underestimate actual unemployment and typically fluctuated around $2 \%$. As an example, in the 1921 recession, the seasonally-adjusted unemployment rate among trade union members peaked for a few months at $27 \%$ (counting unemployed on the last day of a month, including those with spells lasting less than half a month), whereas the figure based on public employment office data peaked at around $4 \%$. Because of all this, we do not use unemployment data to obtain indicators of early-life conditions. (A more general disadvantage of unemployment is that since steady- 
state frictional unemployment acts as a lower bound, contrasts between years of moderate economic expansion and years of fast expansion may be hard to detect.)

An alternative explanation for a long-run effect of the business cycle at birth is that in recessions, the quality of neonatal care in the hospital is lower. This would not affect the validity of our causal inference but it may affect the interpretation of the findings. Kungliga Medicinalstyrelsen (1918-1931) provides the total annual budget of the hospital in Uppsala in nominal terms. It turns out that this budget monotonically increased with the exception of the years 1921-1923. However, the latter is due to deflation in those years. In real terms the series is a slowly increasing linear function of time.

Our approach requires that business variation in birth years is not systematically related to cohort-specific societal events or policy reforms during childhood or adulthood. Such a relation could arise by coincidence, e.g. if the cohort born right after a major recession is the first cohort exposed to a war or an educational reform. However, Sweden did not participate in World War II, and, as noted above, the great depression did not have a severe contemporaneous effect. Primary education in elementary schools took 7 years and was compulsory. In our time frame there were no major elementary-school reforms, with the potential exception of a reform in 1936 in which a specific exemption to the compulsory nature was abolished. This concerned the option to drop out after some years of elementary school in case of severe poverty of the child's household (see Ahlström, 2011 , for details). However, for our purposes it is important to point out that in the years prior to the reform, the exception was only used in about $3 \%$ of all cases, concentrated in rural areas elsewhere in Sweden. Moreover, such dropout typically occurred in the final years of primary education. Jonsson (1991) does not find discontinuities in long-run economic and sociological outcomes as a result of this reform. Concerning our analyses we should first of all point out that we control for parental social class, and that poverty or adverse conditions at schoolgoing ages are not the same as birth in a recession, so that a relation between drop-out and cyclical conditions at birth is not expected. The ability score variable is measured in third grade and hence is observable even for those who subsequently drop out. The lowest value of the "attained level of education" variable in our data aggregates any drop-outs with those who have completed primary education.

In our time frame, the main reform in secondary education took place in 1927. This opened up the route to higher education for women (see e.g. Johansson, 2004, and references therein). This is an additional reason for why in this paper we restrict attention to men. 


\subsection{The regional and historical societal context of the births}

In our birth cohort observation window 1915-1929, Sweden had about 6 million inhabitants. The agricultural, industrial and service sectors each employed about one-third of the total workforce. See e.g. Lobell, Schön and Krantz (2007) for details of the Swedish economy in these years and the surrounding decades.

National Central Bureau of Statistics (1969) and Statistics Sweden (1999) provide yearly historical data and detailed descriptions of demographic developments in Sweden. Sundin and Willner (2007) contains an extensive and detailed history of public health in Sweden. The living conditions in the 1920s were relatively good in comparison to most other countries at the time and in comparison to many developing countries today. Life expectancy was among the highest in the world, and infant mortality among the lowest (around 5\%). The public health care system was quite modern, with institutionalized maternal and child health care in urban areas. So-called district nurses provided preventive care to children at school and mothers at home.

In contrast to this, Sweden did not have modern labor market institutions in the birth cohort observation window. As noted above, there was no UI system. For income support, people without work had to rely on charities, informal help from the social network, trade union support, or workfare, where in the latter two cases the amount of support was usually meager. Municipalities also provided social assistance for needy individuals, but individuals without work as such were not regarded to be sufficiently needy. Notice that the absence of generous income support for these groups means that the business cycle is a relatively powerful determinant of household income. This strengthens the usefulness of our empirical approach to study effects of economic conditions early in life.

We now turn to societal conditions in Uppsala in the birth cohort years. At the time of birth, most individuals in our data resided in the city or in an area around the city. This area includes Uppsala Distrikt, whereas it is embedded in Uppsala county (Län), which is one of the geographically smallest of the around 20 counties of Sweden.

In the years 1915-1929, the population of the city of Uppsala was stable at the level of around 30,000 inhabitants (see National Central Bureau of Statistics, 1915-1931). ${ }^{8}$ The municipal infant mortality rate fluctuated somewhat around $5 \%$, but it is typically slightly lower than the national figure. The population of

\footnotetext{
${ }^{8}$ The statistics pertaining to Uppsala and its regional entities were digitized by the authors and are available upon request.
} 
Uppsala county was also rather stable, at around 135,000. Its (infant) mortality rates were similar to those in the city.

The two largest sectors in the city's labor market were manufacturing ("crafts and industry") and trade ("transport and communication"), occupying $45 \%$ and $25 \%$ of the workforce, respectively (Modin, 2002). The largest employer was a bicycle factory. In the parishes around the city, agriculture was dominant. Electricity was available everywhere. However, working class families typically lived in small apartments, and these were often subject to overcrowding, poor ventilation and bugs. See also Ullenhag (1984) for an overview of Uppsala's economic development in the period until 1921, Isacson and Magnusson (1996) for a historic overview of local labor market issues in the period 1910-1940, and Westrin (1920) for a more general overview of life in Uppsala.

For our purposes, transitory deviations in local GDP may be more powerful than national GDP deviations. However, such data are not available for our birth cohort years. Data are available on numbers of individuals who received income support or temporary housing accommodation from the municipality, and on the corresponding municipal budgets, but these figures are dominated by the elderly, mentally ill, and/or alcoholics (see National Central Bureau of Statistics, 1915-1931). Fluctuations in the local mortality rate are dominated by the 1918 influenza epidemic, while annual numbers of infant deaths are too small to be informative about contemporaneous conditions (and only capture infants with extreme health problems anyway).

\section{Associations between indicators at birth}

\subsection{Birth cohort composition over the business cycle}

In Subsection 2.2 we argued that the association between the state of the business cycle early in life and outcomes later in life provides evidence of causal long-run effects of economic conditions early in life. However, causal inference based on comparisons of individuals born at different stages of the cycle requires that the composition of newborns is invariant over time, at least after conditioning on observed individual characteristics and after controlling for time trends that may reflect secular changes in society regarding fertility. More precisely, the distribution of unobserved predetermined family background determinants of outcomes later in life among conceived children should not depend on the business cycle. ${ }^{9}$

\footnotetext{
${ }^{9}$ Clearly, the composition in terms of variables that may depend on the state of the cycle and that are realized during pregnancy or at birth, such as birth weight, may vary with the
} 
If this requirement is not satisfied then cyclical variation in the distribution of systematic unobserved determinants of outcomes later in life may lead to biased inference. For example, parents with favorable unobserved characteristics (like a high awareness of the health perils of smoking) may, for some reason, less often have offspring during recessions, leading to a long-run association between the business cycle at birth and high-age mortality, unless the characteristic is captured by an observed explanatory variable. Between-cohort variation in the composition of newborns may also arise because of fine-tuning of fertility choices over the business cycle or because of changes in stillbirth rates or abortions over the cycle.

Before examining the evidence that we gather on this issue, notice from Subsection 2.2 that macroeconomic fluctuations had a higher frequency than nowadays, making it difficult for individuals to fine-tune their fertility behavior towards this. In addition, fertility control was less common or at least less effective than nowadays. In fact, there is some evidence of deliberate fertility responses in late19th century Sweden to infant mortality in the household. Specifically, the rate of getting a third child jumps to a higher level upon death of the second child (Kolk, 2009). However, even if second children die more frequently during recessions, the estimated increase in fertility does not perceivably influence the probability that the third child is born in a boom.

Reliable information on the prevalence of stillbirths and spontaneous abortions is notoriously hard to obtain. In our study, their role may be less relevant than in other studies of effects of early-life conditions on mortality at high ages. As noted above, among all countries and all eras up to World War II, Sweden in our birth cohort years had one of the lowest infant mortality rates ever. In the period 1900-1930, the recorded stillbirth rate was as low as $2.5 \%$, and it was remarkably constant across years (see Fellman and Eriksson, 2006). In contrast, extreme events like famines early in life may lead to peaked stillbirth rates and perinatal mortality and strong ensuing dynamic selection of the fittest in the cohort. In our study, such selection would typically lead to an under-estimate of the quantitative effects of economic conditions at birth on outcomes after birth.

In the empirical analysis in this subsection, we start with investigating the association between fluctuations in cohort sizes and the business cycle, following the idea that such an association is indicative of systematic changes in the underlying composition. (For example, Saugstad, 1999, shows that in Denmark, changes in the composition of newborns go along with changes in birth rates.) After this, we discuss direct evidence on the composition. We know from Van cycle. 
den Berg, Doblhammer and Christensen (2011) that the long-run business cycle effect on CV mortality is primarily driven by the state of the cycle in the three final months of pregnancy. Hence, we examine the cycle in the year prior to birth as well as the cycle in the birth year. In this subsection there is no compelling reason to restrict the evidence to boys only. Fertility decisions were made without knowledge of the offspring's gender. Fluctuations in the sex ratio are of a much smaller order of magnitude than fluctuations in birth rates or in the distribution of observable characteristics among newborns in our sample. For reasons of statistical efficiency we therefore use data on male and female births together in the analyses of this subsection.

In our birth cohort years, the national birth rate displays a trend reduction from about 0.021 to 0.016 per year (so a relative reduction of about $25 \%$ ). We decompose this series to obtain the deviation from the trend. The correlation between the yearly deviation in the birth rate and our annual business cycle indicator (i.e., the deviation in the log annual real per capital GDP) equals 0.02 and is not significant ( $\mathrm{p}$-value 0.94). The correlation with the cyclical indicator in the pre-birth year equals 0.05 (p-value 0.86). In fact, the birth rate was almost linear in the period 1915-1929, with as only notable deviation an increase in the years 1920 and 1921. The latter presumably reflects the increase in the marriage rate in the aftermath of World War I. Incidentally, in the period we consider, the national marriage rate is not correlated with the business cycle indicators either (correlations -0.28 and -0.11 with p-values above 0.3 ).

To shed more light on the composition of newborns over the business cycle, we consider the social class of parents of newborns. This information is not available on a national level, so we confine ourselves to our UBCoS sample. In our empirical analyses in the paper we control for the parents' social class, so that the results are unaffected by any systematic selection of births by social class across cohorts. Nevertheless, the extent of selection by social class may be indicative of other systematic differences across cohorts. We therefore proceed by estimating the distributions of social class per birth cohort year and correlate the estimated fractions to the business cycle in that year and the previous year. If we ignore the fact that the distribution per year is estimated rather than known, then the only significant effect is a negative effect of the current cycle on the relative birth rate among those with social class 3 (lower non-manual occupation). There are no effects for the other (higher or lower) six social classes, and no effects from the cycle in the year before the birth year. In fact, social class 3 is the smallest class in the sample. Their number of births per year fluctuates around 60. With a birth rate below $2 \%$, the fluctuations across years may well be dominated by sampling 
error (of births from mothers sampled from a meta-population of mothers with social class 3$)$.

Figure 2 displays the distribution of social class per birth cohort year and the business cycle. For expositional reasons we aggregate into three classes: high $=\{1,2\}$, medium $=\{3,4\}$, and low $=\{5,6,7\}$. We conclude that there is no relation between the business cycle and the distribution of parents' social class among newborns.

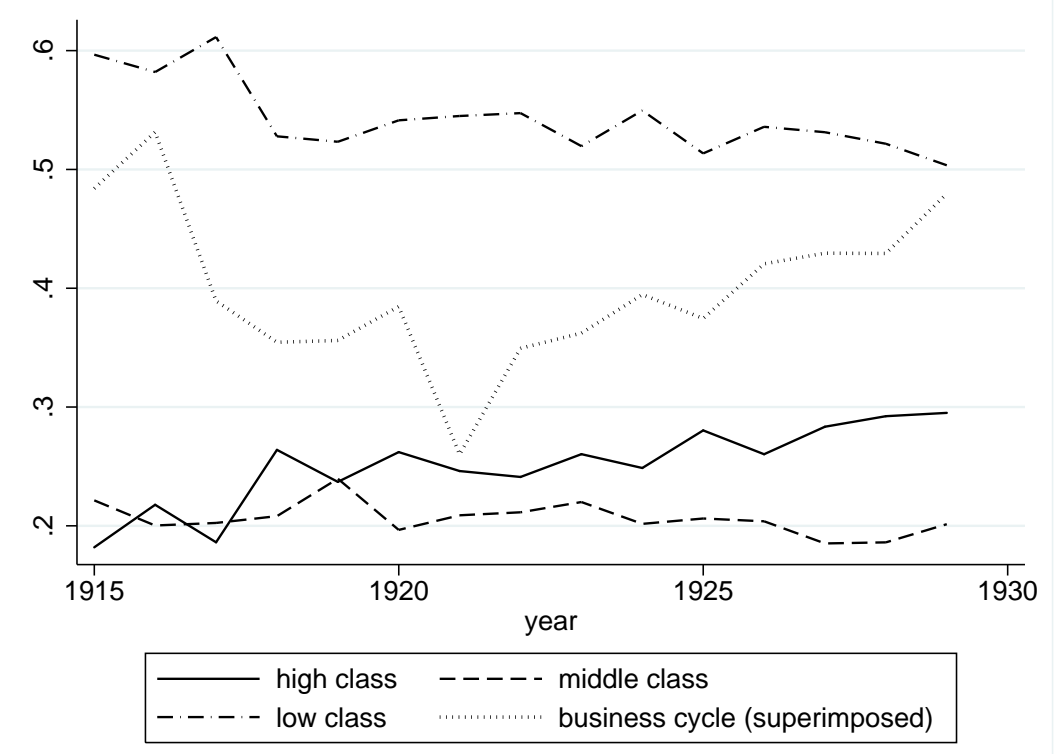

Figure 2. The composition of newborns in terms of their parents' social class, and the business cycle.

Other studies with data from Northwest Europe from similar periods also fail to find that the social-class composition of newborns is systematically related to fluctuations in macro indicators of early-life conditions. Van den Berg, Lindeboom and López (2009) examine how the size and the composition by social class of a birth year cohort changes with the cyclical indicator of the business cycle at birth. Their data are from the Netherlands and contain the social class of the parents at the moment of birth. They conclude that there are no such changes. Kåreholt (2001) studies Swedish birth cohorts from 1897-1938 and examines whether the fraction of newborns whose father had a blue (vs. white collar) occupation varies with the state of the business cycle as measured by the annual change in the inflow into poor relief. The results show that there is no significant variation, neither among male nor among female newborns. Van den Berg, Doblhammer and Christensen (2011) conclude that in Denmark in the years 1873-1906 there 
was no relation between the business cycle on the one hand and the birth rate and the composition of newborns in terms of observed personal characteristics on the other. However, Dehejia and Lleras-Muney (2004) report evidence that in recent years the birth rate among individuals with higher education or status may be higher in recessions. At first sight this contrasts to our findings. To explain their findings they mention that opportunity costs are lower in recessions. However, recall that Sweden in our birth cohort years did not have unemployment benefits, so that a job loss would immediately lead to time-consuming efforts to obtain alternative sources of income. Moreover, as mentioned above, macroeconomic fluctuations had a higher frequency than nowadays, complicating the fine-tuning of births as witnessed by the absence of a relation between marriage rates and the business cycle, and fertility control was less effective than nowadays.

The evidence of this subsection suggests that the composition of newborns does not vary systematically over the business cycle. We end this subsection by noting that the panel data model estimations with sibling (or mother) specific effects that we perform in the remainder of the paper are insensitive to householdspecific selective decisions towards fertility over the business cycle.

\subsection{Birth weight determinants: the business cycle and personal characteristics}

Birth weight is realized at birth, but its determinants exert their influence before birth. Household and family-specific conditions which include genetic characteristics capture a major share of the variation in individual birth weight. For example, the correlation of birth weight across siblings is known to equal 0.5 (see Magnus, Bakketeig and Skjærven, 1993). Currie and Moretti (2007) demonstrate significant intergenerational correlations of birth weight after controlling for personal characteristics. Magnus et al. (2001) argue that the heritability coefficient of birth weight is bounded from below by 0.25 .

Countless articles have been published focusing on specific determinants of birth weight (see e.g. Kramer, 1987, for a survey and meta-analysis). Examples of such determinants are housing conditions, parental social class, exposure to pollution, cigarette and/or alcohol consumption, and the mother's stress level. Many of these articles focus on the prevalence of "low birth weight" (i.e., weight below $2.5 \mathrm{~kg}$ ) as the binary outcome of interest. This is not a common outcome but it is important from a public health point of view. Since our sample is a modestly sized random sample of newborns, it is not particularly informative on low birth weight. In the sample, $4.37 \%$ have low birth weight. Only 139 boys (or 
$1.9 \%$ of the sample) have a birth weight in in the symmetric 150 gram interval around the 2500 grams threshold, so we are not in a position to reliably estimate effects on low birth weight of interventions that increase birth weight with say 50 grams for those with a weight around this threshold. In fact, our data do not contain information on specific behavioral low birth weight determinants, apart from those captured by the characteristics listed in Table 1 above. Among the latter, the parents' social class can be seen as an omnibus variable for all household and family-specific behavioral background conditions.

In our analyses we consider birth weight variation over the full range. All results are insensitive to exclusion of low birth weight individuals. Interestingly, recent evidence (Skjærven, 2011) has demonstrated that the intergenerational association of birth weight is uniformly strong in the normal range, i.e. above 2500 grams, whereas it is almost absent within the low birth weight range.

For our purposes it is particularly interesting to examine the effect of the business cycle on birth weight. Notice that, contrary to some of the birth weight determinants mentioned above, the business cycle is exogenous. ${ }^{10}$ Indeed, as noted in Section 1, it is an instrumental variable for inference on the causal effect of the endogenous economic conditions early in life. As noted above, the business cycle at birth has been found to exert much of its influence during the final trimester. The literature on famine effects has shown that the nutritional conditions in the third trimester of pregnancy are also a major determinant of birth weight (see e.g. Lumey, Stein and Susser, 2011). Kuzawa (2008), on the other hand, claims that maternal nutrition during pregnancy matters less for birth weight than nutritional status at the time of conception. We therefore consider the cycle in the year prior to birth as well as the cycle in the year of birth.

In fact, it is not clear a priori whether purely economic conditions can be expected to exert a major effect on birth weight. Contemporary birth weight values are in the same ball park as those in the past. The mean birth weight among all newborns in Sweden in 1980 equals 3490 grams (Kramer, 1987) whereas in our data (with mean birth year 1922) it equals 3413 grams. So in a period of almost 60 years, mean birth weight increased by only 77 grams (or $2 \%$ ), whereas real per capita GDP witnessed an almost five-fold increase (461\%). ${ }^{11}$ (The fraction with low birth has fluctuated around $5 \%$ in this whole era.) A recent systematic literature review by Margerison Zilko (2010) on the effects of macro-economic

\footnotetext{
${ }^{10}$ This is supported by the result from Subsection 3.1 that the cycle does not influence the composition of newborns.

${ }^{11}$ To some extent a beneficial effect of economic changes may be mitigated by adverse changes in lifestyle, such as an increase in cigarette smoking by pregnant women.
} 
contractions on birth outcomes concludes that the evidence is inconclusive (in fact, the outcomes considered in that literature mostly concern low birth weight, neonatal mortality and the secondary sex ratio). ${ }^{12}$ Our null hypothesis is therefore that there is no effect of the business cycle, whereas the alternative is that the causal effect on birth weight is positive.

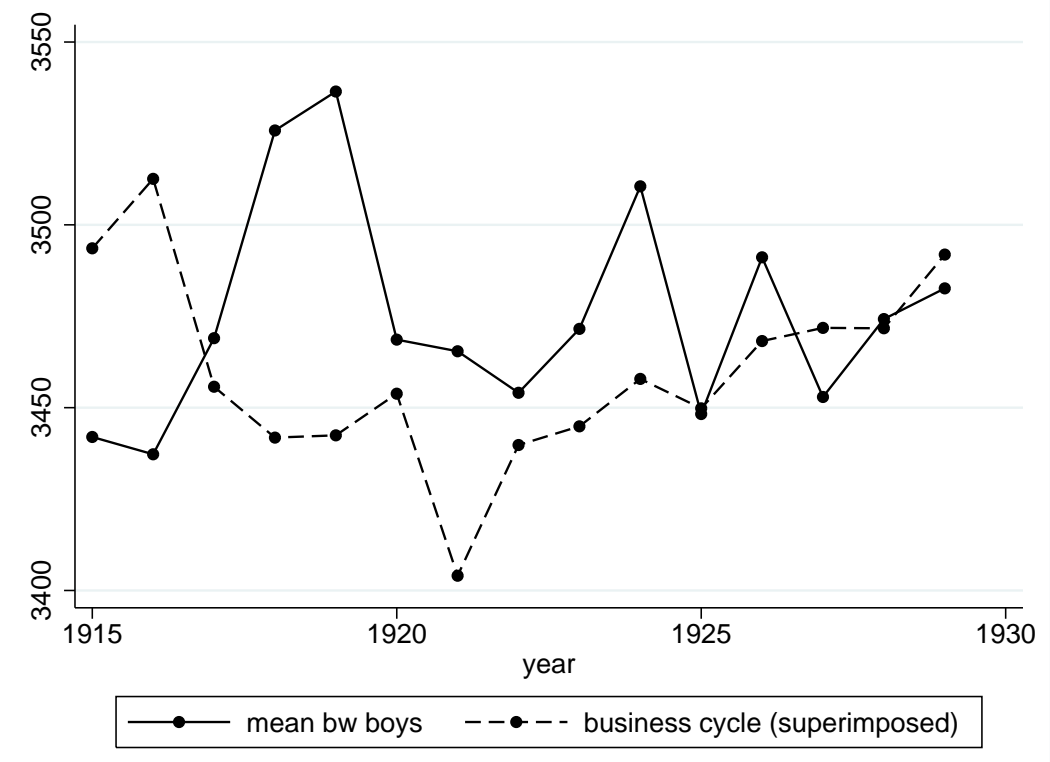

Figure 3. Mean birth weight among boys and the business cycle.

To proceed, we calculate the mean birth weight per birth cohort year in our sample of males and relate this to the business cycle. Figure 3 displays the two time series. It turns out that there is no significant correlation between them. The same applies if we consider the cycle in the year prior to birth. In fact, in the present subsection, the effect of the latter is always insignificant but has the

\footnotetext{
${ }^{12}$ Abu-Saad and Fraser (2010) survey studies and meta-studies on effects of maternal nutrition interventions on birth outcomes including birth weight. They conclude that the evidence is far from consistent, and that parental social class is a much more important determinant of birth outcomes. In our data, the mean birth weights among those with low and high social class are 3378 and 3488, respectively. The difference of 110 grams is in line with the small increase of mean birth weight in between the 1920s and 1980. Note that these figures are small in comparison to the birth weight standard deviation of 558 grams. A number of other studies has examined effects of the mother's welfare benefits or the generosity of welfare on birth weight (e.g. Currie and Cole, 1993, and Kaestner and Lee, 2005). Such effects are often found to be absent or slightly positive. Since welfare dependency may cover a substantial number of years before and after birth, we expect these effects to be in-between the effect of the business cycle at birth and the effect of social class.
} 
same sign as the effect of the cycle in the birth year.

Figure 4 displays nonparametric kernel density estimates of the birth weight densities among males, stratified by whether the business cycle indicator in the birth year is positive (boom) or negative (recession). These estimates use an Epanechnikov kernel and Silverman's rule-of-thumb bandwidth. The densities are virtually equal. This confirms that there is no effect of the cycle.

In the weeks after birth, most babies with a very low birth weight die. It appears that the corresponding survival fractions do not depend on the cyclical indicator at birth though it should be kept in mind that the relevant number of babies in the sample is low. As an example, among the (47) individuals with birth weight below 1700 grams, the fraction of survivors until age 3 is $21 \%$ if born in a recession and $22 \%$ if born in a boom.

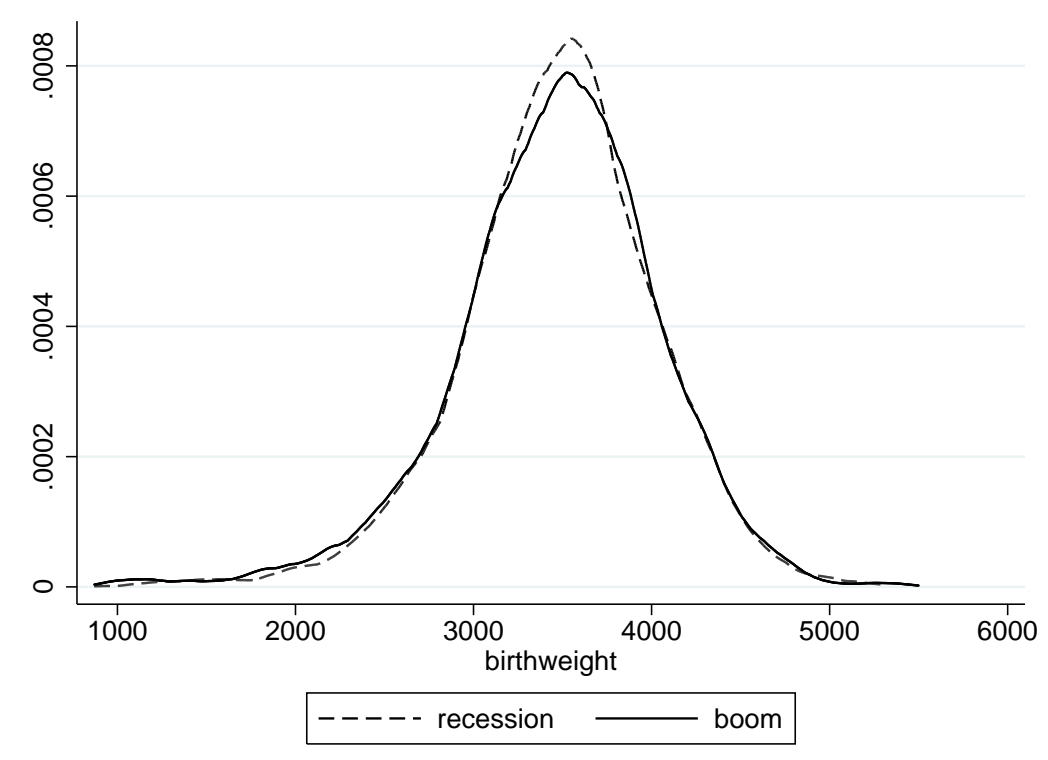

Figure 4. Nonparametric estimate of the density of birth weight, by whether real GDP per capita was above or below its trend value.

Table 2 presents estimates of regressions of log birth weight on the business cycle at birth as well as on other determinants. They confirm that the business cycle has no effect on birth weight. The sign of the coefficient is opposite to the sign under our alternative hypothesis. More importantly, the coefficient is not significantly different from zero. The ensuing magnitude of the effect is negligible. A shift of the cyclical indicator from its 25 th to its 75 th percentile involves a change of 0.07 of the indicator, implying a $0.3 \%$ change in birth weight. ${ }^{13}$

\footnotetext{
${ }^{13}$ The estimated standard errors are virtually identical to those obtained with a cluster-robust
} 
Additional analyses confirm that the business cycle does not have a significant effect on the probability of low birth weight (recall that the latter is a rare outcome in our sample). Furthermore, a birth weight regression for the subsample of survivors until age 3 produces virtually identical results as in Table 2 .

The effects of the other covariates on birth weight are as expected. The parents' social class has a significant effect. The time trend has no effect, confirming the fact that mean birth weight barely increases over time. If the mother was relatively old at birth and/or she was married, then the birth weight is significantly higher. The season of birth does not have an effect on birth weight. The estimated effect of the business cycle does not depend in a notable way on whether these other characteristics are included or not. In a sensitivity analysis we include the interaction between the business cycle and the parents' social class, but its effect is insignificant (t-value 0.2). We also consider the business cycle in the year before birth and weighted averages of both cyclical components (using the time distance from the birth date to January 1 as a weight), but this does not change the above findings. The results are robust with respect to functional forms (e.g. regressing birth weight in levels rather than logs) and the inclusion of other covariates. We conclude from all this that there is no causal effect of the business cycle at birth on birth weight. This is consistent with the evidence reported earlier in this subsection, including the literature review of Margerison Zilko (2010).

As noted in the previous subsection, an association between birth weight and the business cycle might be affected by household-specific behavior towards fertility over the business cycle. For example, some households may fine-tune their fertility decisions on private expert knowledge about the state of the cycle in the next year. Controlling for observed covariates capturing such behavior deals with this. Recall also that the social-class composition of newborns does not change over the cycle. Concerning unobserved determinants we may deal with this issue by restricting attention to within-household variation in birth weight and the business cycle at birth, exploiting the fact that siblings are identified in the data. Table 8 in the Appendix presents estimates of Fixed Effects panel data models, allowing for a mother-specific fixed effect that may be correlated to the observed covariates including the state of the cycle at birth. The corresponding sample is much smaller than in Table 2, since only 933 mothers have multiple sons in the data. Accordingly, the resulting estimates are less precise and less robust to the choice of regressors than those in Table 2. The estimates in Table 8 are for the

standard error estimator that clusters by year of birth, i.e. that allows for arbitrary correlations between individual outcomes within birth year cohorts. This robustness result applies to all OLS regressions in the paper. 
Table 2: OLS estimates of regression model for the log individual birth weight

\begin{tabular}{|l|rll|}
\hline \hline & & & \\
& & & \\
& & & \\
\hline & & & \\
logt. (birt.error) & $\mathrm{t}$ \\
business cycle at birth & -0.00006 & $(0.0029)$ & 0.0 \\
social class at birth (inverse scale) & -0.045 & $(0.034)$ & 1.3 \\
birth in city & -0.0033 & $(0.0014)$ & 2.4 \\
mother's age, at birth & -0.0025 & $(0.0043)$ & 0.6 \\
mother married, at birth & 0.0025 & $(0.00035)$ & 7.1 \\
birth in fall & 0.020 & $(0.0063)$ & 3.2 \\
birth in winter & 0.0058 & $(0.0060)$ & 1.0 \\
birth in spring & -0.0015 & $(0.0058)$ & 0.3 \\
& 0.0018 & $(0.0058)$ & 0.3 \\
\hline sample size & & & \\
& & & \\
\hline \hline
\end{tabular}

Note: the columns denoted by "t" give the t-values. Constant term not reported.

same set of regressors as in Table 2, but also for a subset of regressors that can be expected to vary frequently and exogenously across sons of a given mother while excluding regressors that have been found to be irrelevant in Table 2. The results do not change in a relevant way if the mother's marital status is included. In all cases, the business cycle has no significant effect on birth weight, and the size of the coefficient is again small.

\subsection{Conceptual framework}

The finding that business cycle and birth weight are independent variables in the population facilitates the econometric analysis of their effects on CV mortality and other outcomes. For example, if higher-order terms in the specification of the CV mortality rate as a function of business cycle and birth weight are ignored then the estimates are less likely to be affected by that than if there were multicollinearity. More importantly, the above finding helps to interpret the results on $\mathrm{CV}$ mortality and other outcomes in terms of underlying determinants. In this subsection we develop a framework for the causal effects between the variables we consider, and we examine the implications of the independence of birth weight 
and the business cycle. For ease of exposition, in this subsection, we do not consider the variables that are realized in between birth and death such as childhood cognitive ability and the attained level of education.

The key causal variable is the nutrition in utero and shortly after birth (including the associated stress level; for convenience we refer to all of this as nutrition at birth). Broadly speaking, we distinguish between three sets of determinants of the quality and quantity of nutrition at birth, to the extent that this quality and quantity are important for late-life health. First, (1) there is the inherited biological and genetic setting, say $B$, influencing the build-up of the body and the ease with which nutrients are extracted in utero. Secondly, (2) we consider the transitory economic conditions $E$ around the time of birth. Thirdly, (3) we consider steady-state income and wealth of the household $S$, including its lifestyle, housing conditions, exposure to pollution and so on. This distinction does not extend to the era before conception. Notably, wealth may be influenced by the genetic predisposition of the ancestors, whereas wealth of the grandparents may have led to epigenetic changes among the parents that may be inherited by the child. Concerning the period around birth, we assign for now any transitory conditions that are not driven by economic changes into the third category, tacitly assuming that they are a function of the steady-state non-biological household-specific conditions. Epigenetic changes in the child are not considered to be determinants of nutrition at birth but rather as possible outcomes of the above determinants. Notice that we expect direct causal effects of each of the three determinants on the CV mortality outcome.

The business cycle only affects the second determinant $E$. Conversely, birth weight in the normal range does not affect any of the determinants but instead it may potentially depend on each of them. However, from the previous subsection we know that it does not depend on $E$. Now consider the social class of the parents' household. One may argue that this is a good summary measure of the third determinant $S$. In particular, it does not depend on transitory economic conditions around birth (although it may depend on the genetic background via previous generations). Now recall that we take nutrition at birth to be a function of $B, E$ and $S$. If, in the empirical mortality model, we use the observed cycle at birth to capture $E$ and the observed social class to capture $S$, and if we also include birth weight in the model, then birth weight may represent $B$ (to the extent that biological determinants are not already captured by social class). In other words, if we condition on the cycle and social class as explanatory variables for CV mortality, then the effect of birth weight may capture the CV mortality effects throughout life of the biological and genetic background insofar as this 
background favored circumstances in utero.

A caveat is in order. Recall that we assume that family lifestyle characteristics and idiosyncratic shocks that affect birth weight can be captured by social class. To the extent that in reality they are not related to social class, their causal effect on the outcomes of interest may be captured by the estimated effect of birth weight. More in general, birth weight is likely to be a noisy measure of the relevant sets of genetic and long-run income and wealth determinants $B, S$. Using such a measure as an explanatory variable may introduce a correlation between the explanatory variables and the residual term in the mortality model, making estimates inconsistent. ${ }^{14}$ This issue is ignored in much of the literature in which birth weight is used as an explanatory variable. We can deal with this at least to some extent by exploiting the fact that we observe siblings in the sample. If the "noise" in the birth weight effect is identical across siblings then fixed-effect estimation methods using within-family variation are not sensitive to this. In fact, if the line of reasoning of the previous paragraph is correct then birth weight itself should have a small coefficient in such analyses, because both its determinants $B$ and $S$ are mostly family-specific in the normal range of birth weight.

Of course, there may be aspects of early-life conditions that are not related to any of the three sets of determinants $B, E$ and $S$ and that are not reflected in the birth weight. Such aspects will not be captured by the estimated effects of the business cycle, birth weight or social class. Instead, they give rise to unobserved heterogeneity in the CV mortality analysis. To the extent that they are householdspecific, this is dealt with by fixed-effect estimation methods.

\section{Long-run effects on cardiovascular mortality}

\subsection{Estimation results for the individual CV mortality rate}

Our model specifications for the individual CV mortality rate follow those in the literature. Age is measured in days, so we take it to be a continuous random variable. Let $\tau$ denote current calendar time and let $\tau_{0}:=\tau-t$ be calendar time at

\footnotetext{
${ }^{14}$ Let birth weight be a function of $B$ and $S$, and let $\mathrm{CV}$ mortality be a function of $B, E$ and $S$. The first function can be used to obtain an expression for $B$ in terms of birth weight and $S$, and this can be substituted into the mortality function, to obtain a function of birth weight, $E$ and $S$, which can be used for inference on causal effects of $E, B$ and $S$. Such inference is only possible if birth weight is perfectly explained by $B$ and $S$, which is of course a strong assumption.
} 
birth. We may express the (CV) mortality rate $\theta$ of an individual at a given point of time in terms of the prevailing age $t$, individual background characteristics $x$, current conditions $z(\tau)$, early-life indicators $c(\tau)$ with $\tau$ close to $\tau_{0}$, unobserved individual characteristics or frailty $V$, and various interaction terms. For example,

$$
\log \theta(t \mid x, z, c(\tau-t), V)=\psi(t)+\beta_{1}^{\prime} x+\eta^{\prime} c\left(\tau_{0}\right)+\beta_{2}^{\prime} z(\tau)+\log V
$$

where $\eta$ is the parameter of interest. This is a Mixed Proportional Hazards (MPH) model with time-varying regressors $z$.

Table 3: Cox-PL parameter estimates of PH Models for the individual CV mortality rate

\begin{tabular}{|c|c|c|c|c|c|c|}
\hline variable & $\begin{array}{l}\text { pe } \\
\text { est. }\end{array}$ & $\begin{array}{l}\text { rsimoniou } \\
\text { (st.error) }\end{array}$ & $\mathrm{t}$ & est. & $\begin{array}{l}\text { tended } \\
\text { (st.error) }\end{array}$ & $\mathrm{t}$ \\
\hline $\log ($ birth year-1914) & -0.20 & $(0.039)$ & 5.1 & -0.21 & $(0.040)$ & 5.3 \\
\hline business cycle at birth & -1.58 & $(0.43)$ & 3.7 & -1.56 & $(0.43)$ & 3.6 \\
\hline $\log$ (birth weight) & -0.45 & $(0.17)$ & 2.7 & -0.42 & $(0.17)$ & 2.5 \\
\hline cycle at birth $* \log$ (birth weight) & 6.11 & $(2.29)$ & 2.7 & 6.28 & $(2.32)$ & 2.7 \\
\hline social class at birth (inverse scale) & 0.061 & $(0.015)$ & 4.1 & 0.044 & $(0.017)$ & 2.5 \\
\hline cycle at birth $*$ social class at birth & & & & -0.031 & $(0.22)$ & 0.1 \\
\hline birth in city & & & & -0.021 & $(0.054)$ & 0.4 \\
\hline mother's age, at birth & & & & -0.00036 & $(0.0045)$ & 0.1 \\
\hline mother married, at birth & & & & -0.14 & $(0.076)$ & 1.9 \\
\hline birth in fall & & & & 0.036 & $(0.077)$ & 0.5 \\
\hline birth in winter & & & & 0.13 & $(0.073)$ & 1.8 \\
\hline birth in spring & & & & 0.084 & $(0.074)$ & 1.1 \\
\hline sample size & & 6318 & & & 6314 & \\
\hline log partial likelihood & & -11840.9 & & & -11829.0 & \\
\hline
\end{tabular}

Note: explanatory variables that are interacted are measured in deviation from their mean value. The columns denoted by "t" give the t-values.

We capture long-run secular and current trend effects by way of a log-linear 
function of the birth year. We could as well take a function of $\tau$. A seemingly more general specification with polynomials in $t, \tau_{0}$ as well as $\tau$ would be susceptible to the so-called age-period-cohort identification problem.

In the absence of unobserved heterogeneity, the model reduces to a $\mathrm{PH}$ model, and the parameters $\beta$ and $\eta$ can be estimated with Partial Likelihood Estimation. This means that the age-dependence function $\psi$ (or "force of mortality" or "baseline hazard") is left unspecified when estimating these parameters. Note that the longevity data are left-truncated in the year 1952 because death causes are not observed before that. Furthermore, cause-specific mortality is right-censored by mortality due to other causes. One may question the assumption that such censoring is non-informative on the CV mortality rate conditional on the observed covariates. Wienke et al. (2002) allow unobserved determinants of different causespecific mortality rates to be stochastically dependent. They estimate models with Danish twin data distinguishing between mortality due to coronary heart disease and mortality due to all other causes. They do not find a significant dependence between the unobserved determinants of the two cause-specific mortality rates. We take this as support for our assumption of non-informative censoring of CV mortality.

The first columns of Table 3 present the estimates for the simplest model version. Here, the CV mortality rate depends on the two early-life indicators as well as their interaction and on the parents' social class. In addition, we control for age and a time trend. The estimates in the final columns concern a model with a larger set of covariates.

The first notable result is that the business cycle has a significant effect on the CV mortality rate. Birth in a recession implies a higher CV mortality rate later in life. The magnitude of the estimated average effect on longevity can be inferred by combining the estimates with an estimate of the age dependence function $\psi$. We compare two values of the business cycle indicator, namely the 25 th and the 75 th percentile of its distribution. The difference between these values equals $7 \%$ of real per capita GDP. According to the simple model, the ensuing difference in the CV mortality rate is about $10 \%$. This can be translated into additional months of life if we adopt a parametric model specification (see below) and assume (a) that the estimated parametric specification extrapolates to ages above those observed in our data, and $(b)$ the distribution of the rightcensoring of CV mortality is not affected by the business cycle at birth. With this in mind we obtain an average effect of about 6 to 8 months extra life beyond having reached prime ages. In the absence of other death causes this number would rise to about a year. These numbers are in the same ball park as those 
reported in Van den Berg, Doblhammer and Christensen (2011), who examine CV mortality for the birth cohorts 1873-1906 of twins in Denmark, and to numbers that can be deduced from Van den Berg, Lindeboom and Portrait (2006) who examine over-all mortality for cohorts born in 1815-1902 in the Netherlands. This mutual consistency lends further credence to the use of the business cycle at birth as an indicator of early-life conditions.

As expected, birth weight has a significant negative effect on the CV mortality rate as well. However, the change in birth weight required for an associated few additional months of life is large. The cited literature on the effect of specific interventions on birth weight suggests that improvements of say 100 grams may be feasible among those with low birth weight. Our estimates imply that across the normal range, 100 grams do not suffice to prolong longevity with more than one month, at least if one restricts attention to effects on CV mortality, and keeping the above caveats in mind when translating effects into longevity.

We now turn to the interaction effect of birth weight and business cycle. In the literature on mortality, the object of interest is the log individual mortality rate. Equivalently, the effects of interest are the relative effects on the individual mortality rate. In accordance to this, we focus on interaction effects on the log individual mortality rate, or, equivalently, on interactions of relative effects on the individual mortality rate.

The fact that the interaction coefficient in Table 3 is significant and positive means that birth weight and the business cycle at birth are substitutes in their beneficial relative effect on the $\mathrm{CV}$ mortality rate, in the sense that the effect on $\log \theta$ of a simultaneous improvement in both is smaller in absolute value than the sum of the separate effects. Consider the 25 th and the 75 th percentiles of the distributions of our two indicators of early-life conditions. The difference for the cycle is again 7\% of real per capita GDP, whereas for birth weight it is 650 gram. According to the simple model, an additional 650 gram birth weight for someone born in a recession leads to a CV mortality rate reduction of $13.6 \%$ beyond having reached prime ages. In case of birth in a boom, the reduction is $6.3 \%$. Thus, the adverse effect of low birth weight is more severe if the child was born in a recession.

Again, this can be translated into months of additional life, under the assumptions listed above. Note that duration models like the MPH and PH models postulate a non-linear non-additive relation between the expected longevity and its explanatory variables (see e.g. Van den Berg, 2001). As a result, the estimated models predict interaction effects of birth weight and the business cycle at birth on mean longevity even if the former do not interact in the log mortality rate. It 
turns out that the size of this mechanical interaction effect is opposite to the size of the interaction coefficient in the log mortality rate. Furthermore, the quantitative importance of the mechanical interaction effect is smaller than the effect due to the interaction coefficient which causes mean longevity to increase with 5 more months if birth weight increases with 650 gram in a recession than if it increases with this amount in a boom (so the increase is about 9 months in a recession and 4 months in a boom). Thus, the interaction effect on the mean duration is not an artefact of the model specification.

Table 3 shows that the findings so far are robust to the inclusion of additional covariates. The interaction of the business cycle at birth and social class at birth does not affect mortality. This is an important finding for two reasons. First, if such an interaction were present then it could have been the driving force behind the interaction result in the simple model in the first columns of Table 3. After all, social class influences birth weight. Secondly, the absence of an interaction effect of the cycle and social class suggests that in the present setting, the higher classes were not exempted from exposure to cyclical fluctuations. We also consider interaction effects of birth weight and parental social class, but in accordance to the estimates of Rajaleid, Manor and Koupil (2008) with the UBCoS data, we do not find such effects. ${ }^{15}$ The other covariate effects in the extended model are as expected. Omitting the interaction of cycle and birth weight does not affect the other coefficients. The business cycle in the year before birth does not affect CV mortality. This is in accordance to the literature cited above.

According to the conceptual framework developed in Subsection 3.3, the findings of this subsection translate into an interaction effect of $(i)$ transitory economic conditions at birth and (ii) the inherited biological and genetic setting, in their effect on the log individual CV mortality rate. Basically, economic conditions at birth make a larger difference if the infant is born into a low birth weight family. Note that we control for parental social class which may capture effects of family habits, lifestyle and the long-run wealth level. Thus, a sudden deterioration of economic conditions around the date of birth, leading to a sudden deterioration of nutrition and stress in the household, has more severe long-run effects on CV mortality in families that have a stronger biological vulnerability for CV diseases in the first place. This is a novel result. It may be tempting to interpret it as an interaction between nature and nurture. However, in the light of recent evidence on the effects of early-life conditions on epigenetic outcomes and their possible intergenerational transmission (see e.g. Heijmans et al., 2008),

\footnotetext{
${ }^{15}$ The interaction of birth weight and social class is also studied in Osler et al. (2003). Specifically, following Danish men born in 1953 up to age 49, they do not find an effect on mortality.
} 
the existence of a separate "nature" category is questionable, and accordingly the distinction between nature and nurture has lost much of its meaning. Further, recall that if there are family lifestyle characteristics that affect birth weight and that are not related to social class then the estimated effects of birth weight may include effects of such characteristics. ${ }^{16}$

Van den Berg, Doblhammer and Christensen (2011) find that the correlation between fraternal twins of their unobserved CV mortality determinants is larger if the twin pair is born in a recession. This means that shared background characteristics are more important for CV mortality if the twins are born in a recession. Clearly, this is in agreement with the interaction effect of cycle at birth and birth weight that we find (although the cited study does not control for social class and it is conceivable that its result is driven by a higher sensitivity of low social class parents to the cycle in Denmark in the late 19th century).

We perform some additional sensitivity checks. First, we estimate model versions that allow for unobserved individual characteristics at the individual level. Specifically, we estimate (1) using maximum likelihood estimation, allowing for unobserved heterogeneity $V$ that follows a gamma distribution, and assuming Gompertz duration dependence (so $\psi(t)$ is linear). In longevity studies, these functional forms are relatively uncontroversial. It turns out that the results are similar to those above, the main difference being that the covariate effects and their standard errors are slightly larger in absolute value, as is to be expected (Van den Berg, 2001).

To investigate whether the year of birth has a causal long-run effect on CV mortality on top of the effects of the business cycle and the secular trend, we estimate a model that includes binary birth-year indicators as explanatory variables. With 15 birth years and with regressors for the cycle and the trend, this amounts to 12 additional indicators. Here we exclude interaction effects of birth weight and the business cycle at birth but we control for other covariates. According to a Likelihood Ratio test, these additional indicators do not improve the fit of the model, and the business cycle coefficient does not change much. The latter also applies if we include a squared trend variable instead of the 12 indicators. We also re-estimate the parsimonious model 15 times while excluding all individuals from one of each of the 15 birth years. Again, the results are in accordance with the hypothesis that the model specification is homogeneous across birth years. Adding a quadratic term of the business cycle indicator or of the log birth weight

\footnotetext{
${ }^{16}$ See Fletcher (2012) for an example of unambiguous nature-nurture interaction effects (namely the interaction effect of a certain genotype and the tobacco tax level on tobacco consumption).
} 
does not affect the key findings either. ${ }^{17}$

\subsection{Stratified Partial Likelihood Estimation}

As mentioned above, the association between the business cycle at birth and later outcomes may be affected by selective household-specific behavior towards fertility over the business cycle. In that case, the estimates of the previous subsection may be biased. This is not solved by random effects estimation (like maximum likelihood estimation of a Mixed Proportional Hazards model version). Instead, we use Stratified Partial Likelihood Estimation (SPL). With SPL, unobserved characteristics (or frailty terms, or fixed effects) that are common across siblings do not enter the likelihood function. Hence, estimation does not require the assumption that observed and unobserved explanatory variables are independent. This makes the method useful to deal with selectivity of newborns born at particular stages of the business cycle.

Consider the following model for the log CV mortality rate of individual $i$ in household $j$, which generalizes the $\mathrm{PH}$ model,

$$
\psi_{j}(t)+\beta_{1}^{\prime} x_{i j}+\eta^{\prime} c\left(\tau_{0, i j}\right)
$$

In (2), the term $\psi_{j}$ subsumes all heterogeneity at the household level, including observed and unobserved household characteristics. For example, it may be written as $\xi(t)+\alpha x_{j}+\beta_{2}^{\prime} z(\tau)+\log V_{j}$, with the unobservables $V_{j}$ being potentially dependent on the explanatory variables $x_{i j}$ and the birth years $\tau_{0, i j}$.

SPL maximizes the function obtained by multiplying the within-household partial likelihoods. The function $\psi_{j}$ is unspecified and is not estimated along with the other parameters. See Kalbfleisch and Prentice (1980) and Ridder and Tunalı (1999) for details. In the terminology of Ridder and Tunalı (1999), we face an asynchronous observation scheme made synchronous. They explain complications involved in the use of SPL to study child mortality with sibling data, but since we condition on survival into adulthood, many of those do not apply here. Most importantly, we need to rule out that the death of an older sibling has a direct

\footnotetext{
${ }^{17}$ The data contain a measure of gestational age. We do not use this variable in our main analyses because it is not clear how reliable it is. Its measurement may be the result of a reconstruction by a hospital nurse. have been Alternatively, it may be jointly determined with birth weight, as a function of underlying factors. Its sample correlation with birth weight is about 0.5 whereas it is not correlated to the business cycle. Adding gestational age in the birth weight regression does not affect the business cycle coefficient, and adding it to the CV mortality analysis does not affect the estimated long-run effects of business cycle and birth weight.
} 
causal effect on the mortality rate of surviving younger siblings. Of course, this assumption also applies to the estimates of the previous subsection.

Effectively, SPL only exploits within-household variation in birth weight and the business cycle at birth. Like in fixed effect panel data estimation, the effects of covariates that are common across siblings are not identified. The model specification allows for full interaction of the values of such covariates with the elapsed age $t$ and the unobserved household-specific covariates. Now consider the argument in Subsection 3.3 that birth weight as a long-run determinant of CV mortality mostly captures steady-state household-specific conditions. In that case, the birth weight effect will be captured by $\psi_{j}$, so including it in $x_{i j}$ will result in the corresponding coefficient being zero. This also applies to interaction effects of birth weight and individual-specific determinants, notably $c\left((\tau-t)_{i j}\right)$. Thus, SPL allows us to verify whether the effect of birth weight is primarily household-specific rather than individual-specific.

Table 9 in the Appendix presents the SPL estimates. The sample is much smaller than in Table 3. We therefore only present results for the parsimonious set of regressors. The results are robust with respect to the inclusion of regressors from Table 3 that can be expected to vary frequently across sons of a given mother (notably, season of birth and the interaction of social class and the cycle at birth).

In all cases, the business cycle at birth has a significant effect on CV mortality, in line with the results of the previous subsection. As our analysis is the first ever in which sibling fixed effects are used to deal with the possibility of endogenous fertility in the study of long-run effects, this finding lends further credence to the presence of causal long-run effects. Further, the mutual consistency with the results in Table 3 lends further credence to the use of the business cycle at birth as an indicator of early-life conditions.

In the SPL analysis, birth weight has no effect on CV mortality rate. This applies to the marginal effect as well as to the interaction with the cycle at birth. This confirms that birth weight mostly captures household-specific conditions. 


\section{Childhood ability and education in the path- way from economic conditions at birth to car- diovascular mortality}

\subsection{Determinants of ability: the business cycle at birth, birth weight, and personal characteristics}

As mentioned in the introduction, birth weight has been shown to be positively correlated to cognitive ability as measured by IQ during childhood or school performance. This applies to low birth weight as well as to the normal range of birth weight, controlling for other personal characteristics. The effect of the business cycle at birth on ability or school grades has not been studied yet. Figure 5 presents nonparametric kernel density estimates of the densities of the arithmetic \& geometry school grade (score), stratified by whether the business cycle indicator in the birth year is positive (boom) or negative (recession). The bandwidth is set equal to 2 in order to smoothen oscillations in the functions. The density for those born in a boom is an almost perfect location shift of the density for those born in a recession, the difference equalling about 0.2 of a grade point. This suggests that economic conditions around birth do have a causal effect on ability. For the average of the scores over all subjects areas, the results are essentially the same, although it is slightly less responsive. Henceforth, for simplicity but with some abuse of language, we refer to the math school grade (score) as "the" ability score or simply as ability.

To proceed, we estimate regression models for the ability outcome. Table 4 presents the estimation results. They confirm that economic conditions at birth as well as the biological predisposition (as captured by birth weight) affect ability. The effects are, however, small. Comparing again the 25th and the 75th percentiles of the distributions, the business cycle changes the ability score by 0.15 of a point, while birth weight achieves a 0.10 change, in each specification. These translate into 0.07 and 0.05 of one standard deviation of ability.

The effect of economic conditions at birth can be explained in a number of ways. First, there may be a biological effect of nutrition on brain development in utero. Antonow-Schlorke et al. (2011) provide evidence for this from an experiment with primates. Secondly, such an effect may also be induced shortly after birth. Using data from an intervention trial in Guatemala, Stein et al. (2008) find a significant effect of the provision of a nutritional supplement from birth until 24 months on cognitive ability at age 30 (regardless of education). Thirdly, with 


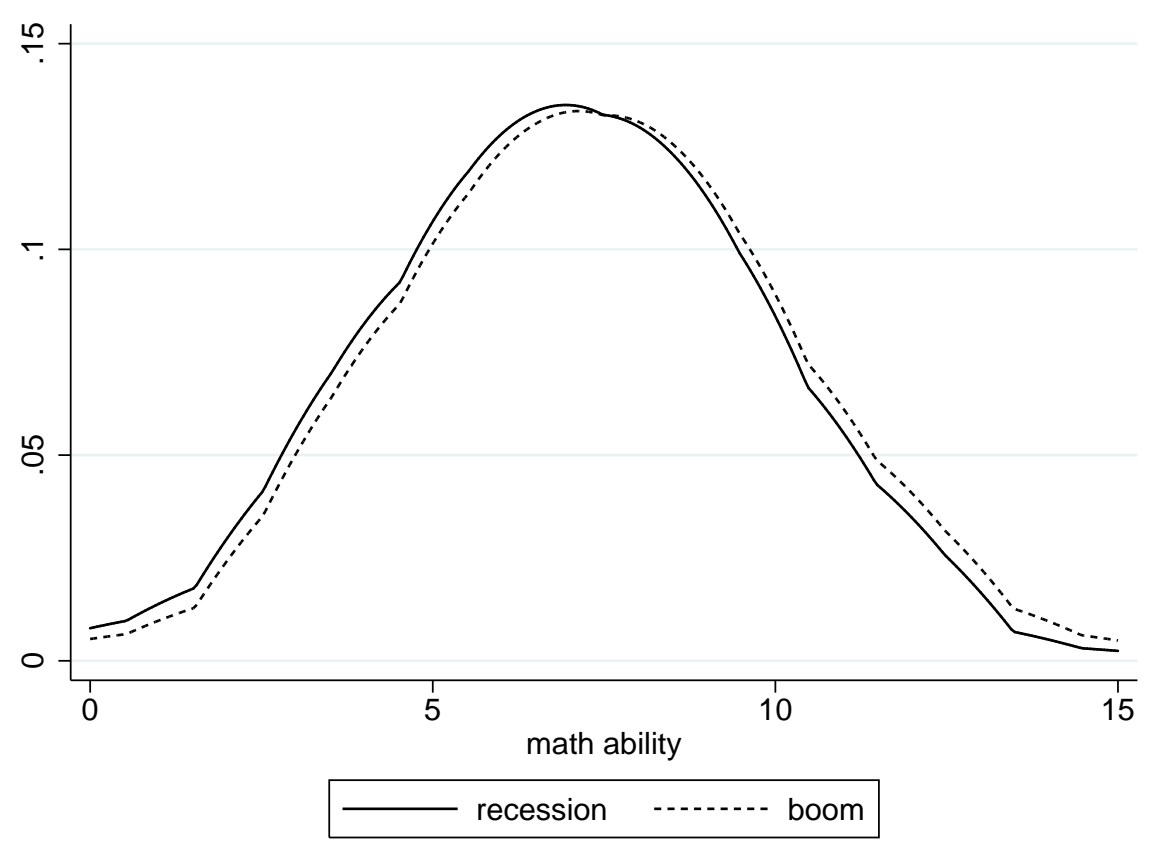

Figure 5. Nonparametric estimate of the density of the ability score among ten year olds, by whether real GDP per capita at birth was above or below its trend value.

favorable economic conditions the quality of the child-mother relationship may be better, and this may improve cognitive abilities of the child. Stams, Juffer and Van IJzendoorn (2002) find evidence for an effect of maternal attachment on cognitive ability among children who were adopted before 6 months of age.

The small size of the birth weight effect is consistent with the systematic literature review of Shenkin, Starr and Deary (2004) concerning birth weight effects on childhood cognitive abilities. The insignificant interaction effect of birth weight and business cycle means that these do not interact in their beneficial effect on ability. Hence, the association between birth weight and ability does not depend on economic conditions at birth. ${ }^{18}$

\footnotetext{
${ }^{18}$ We also estimate a model allowing for a sibling fixed effect that may be correlated to the observed covariates including the state of the cycle at birth and birth weight. Effectively, this amounts to using within-family variation only. The corresponding sample is small because it requires multiple brothers within a family in the school district for whom we actually observe the school grades. We end up with only 578 mothers, jointly having 1323 sons, and the resulting estimates are imprecise and sensitive to the choice of regressors. Shenkin, Starr and Deary (2004) review a few studies with sibling designs and conclude that their findings on the presence of an effect are inconsistent. Oreopoulos et al. (2008) use a very large sample containing over 40,000
} 
Table 4: OLS estimates of regression models for the ability score

\begin{tabular}{|c|c|c|c|c|c|c|}
\hline variable & \multicolumn{3}{|c|}{ parsimonious } & est. & $\begin{array}{l}\text { extended } \\
\text { (st.error) }\end{array}$ & $\mathrm{t}$ \\
\hline log (birth year-1914) & 0.064 & $(0.044)$ & 1.5 & 0.062 & $(0.044)$ & 1.4 \\
\hline business cycle at birth & 2.17 & $(0.51)$ & 4.3 & 2.06 & $(0.51)$ & 4.1 \\
\hline $\log$ (birth weight) & 0.51 & $(0.21)$ & 2.5 & 0.54 & $(0.21)$ & 2.6 \\
\hline cycle at birth $* \log$ (birth weight) & 3.20 & $(3.12)$ & 1.0 & 2.40 & $(3.13)$ & 0.8 \\
\hline social class at birth (inverse scale) & -0.11 & $(0.018)$ & 6.2 & -0.11 & $(0.021)$ & 5.4 \\
\hline cycle at birth $*$ social class at birth & & & & -0.15 & $(0.29)$ & 0.5 \\
\hline birth in city & & & & -0.034 & $(0.064)$ & 0.6 \\
\hline mother's age, at birth & & & & -0.014 & $(0.0054)$ & 2.5 \\
\hline mother married, at birth & & & & 0.15 & $(0.097)$ & 1.6 \\
\hline birth in fall & & & & 0.036 & $(0.090)$ & 0.4 \\
\hline birth in winter & & & & 0.42 & $(0.087)$ & 4.9 \\
\hline birth in spring & & & & 0.31 & $(0.088)$ & 3.5 \\
\hline sample size & & 4376 & & & 4373 & \\
\hline
\end{tabular}

Note: explanatory variables that are interacted are measured in deviation from their mean value. The columns denoted by "t" give the t-values. Constant terms not reported.

The models only explain a small fraction of the variation in ability $\left(R^{2}\right.$ values $\leq 0.03$ ). Notice that the effects of birth weight and business cycle at birth are dominated by the effects of social class and season of birth. The ability score is higher if the boy was born in winter or spring (January-June). This finding is confirmed in Fredriksson and Öckert (2005) who studied cohorts born after 1934. It is explained by the fact that school entry takes place in August of the year in

siblings to study the effect of birth weight (over the full range) on a language skills test score at around age 17. Interestingly, they find a small significant effect in a regression analysis of their full sample but no effect in a sibling fixed effect analysis. Along the lines of our conceptual framework, this suggests that the association between birth weight and ability is mostly driven by family characteristics such as the genetic predisposition. 
which the individual turns 7 .

\subsection{Ability as a determinant of cardiovascular mortality}

This subsection considers (i) whether the long-run effects on CV mortality run indirectly through ability and (ii) whether ability mitigates adverse early-life conditions. An indirect pathway through ability is said to exist if the following set of results is found. First, early-life conditions affect ability. This has already been found in the previous subsection. Secondly, ability affects CV mortality as an explanatory variable in a model that controls for early-life conditions. Thirdly, the coefficients of early-life conditions in the CV mortality model are smaller in absolute value if ability is controlled for than if it is not. The more substantial the reduction in the size of these coefficients, the more important the indirect pathway is, compared to a direct long-run effect. ${ }^{19}$ Finally, a mitigating role of ability is revealed by interaction effects of early-life conditions and ability as determinants of the log CV mortality rate.

The inclusion of ability in the CV mortality model reduces the sample size in comparison to Section 4, since we only use ability score data from the Uppsala school dictrict. To verify that the findings of Section 4 still hold true, we reestimate the model specifications of that section using the school district subsample. It turns out that the coefficients are barely affected. This can be seen from the first columns of Table 5, presenting the estimates of the parsimonious specification (for sake of brevity we do not present the extended specification). The coefficients are as in Table 3. CV mortality is slightly more responsive to the business cycle than it is in the full sample. This may be because households outside of the school district are mostly from rural agricultural areas.

From the second set of columns we observe that ability has a significantly negative effect on CV mortality. However, the estimated effects of business cycle, birth weight and their interaction are unaffected by the inclusion of ability into

\footnotetext{
${ }^{19}$ Quantification of direct vs. indirect effects on hazard rates requires a number of assumptions; see e.g. Lange and Hansen (2011) and Kaufman, MacLehose and Kaufman (2004). (See also Blakely (2002) for an assessment of when results are particularly affected.) In particular, in our case we require that ability is exogenous conditional on early-life conditions and the other covariates. Unobserved determinants of ability are not allowed to affect the CV mortality rate. This could be avoided if an instrumental variable for ability were available, but clearly all observed early-life determinants of ability may be expected to directly affect CV mortality as well. Note further that hazard rate estimation is sensitive to omission of variables, such that estimation of a model without ability typically leads to attenuated coefficients if ability has an effect on the individual hazard rate (Van den Berg, 2001). This may lead to an over-estimation of the importance of indirect effects. As we shall see, we do not find evidence for indirect effects.
} 
Table 5: Cox-PL parameter estimates of PH Models for the individual CV mortality rate with the ability score as a covariate

\begin{tabular}{|c|c|c|c|c|c|c|c|c|c|}
\hline variable & \multicolumn{3}{|c|}{ without ability } & \multicolumn{3}{|c|}{$\begin{array}{c}\text { no interactions } \\
\text { with ability }\end{array}$} & \multicolumn{3}{|c|}{$\begin{array}{c}\text { interactions with } \\
\text { ability }\end{array}$} \\
\hline log (birth year-1914) & -0.19 & $(0.046)$ & 4.0 & -0.18 & $(0.046)$ & 4.0 & -0.18 & $(0.046)$ & 4.0 \\
\hline business cycle at birth & -1.96 & $(0.51)$ & 3.9 & -1.86 & $(0.51)$ & 3.7 & -1.89 & $(0.51)$ & 3.7 \\
\hline $\log$ (birth weight) & -0.59 & $(0.20)$ & 3.0 & -0.57 & $(0.20)$ & 2.9 & -0.55 & $(0.20)$ & 2.8 \\
\hline cycle at birth $* \log$ (birth weight $)$ & 6.78 & $(2.62)$ & 2.6 & 6.83 & $(2.63)$ & 2.6 & 6.86 & $(2.63)$ & 2.6 \\
\hline social class at birth (inv scale) & 0.056 & $(0.018)$ & 3.1 & 0.053 & $(0.018)$ & 2.9 & 0.053 & $(0.018)$ & 2.9 \\
\hline ability score & & & & -0.039 & $(0.015)$ & 2.6 & -0.039 & $(0.015)$ & 2.6 \\
\hline ability score $*$ cycle at birth & & & & & & & -0.19 & $(0.21)$ & 0.9 \\
\hline ability score $* \log ($ birth weight $)$ & & & & & & & 0.051 & $(0.088)$ & 0.6 \\
\hline sample size & & 4268 & & & 4268 & & & 4268 & \\
\hline log partial likelihood & & -7988.9 & & & -7985.5 & & & -7984.9 & \\
\hline
\end{tabular}

Note: sample only includes those for whom ability is observed in Uppsala school district. Explanatory variables that are interacted are measured in deviation from their mean value. The columns denoted by "t" give the t-values.

the model. The coefficient of the business cycle is reduced by $5 \%$ but this is negligible in the light of its standard error. The reduction of the other early-life coefficients is even smaller. ${ }^{20}$ This also applies to SPL analyses (where the sample is small, with 1262 individuals from 555 mothers). In sum, there is no sizeable indirect pathway running through ability. Apparently, the effect of ability on CV mortality is driven by other determinants or components of ability than those captured by birth weight and the business cycle. ${ }^{21}$

It is interesting to compare our estimated effect of ability on CV mortality to

\footnotetext{
${ }^{20}$ These findings are insensitive to monotone transformations of the ability measure as a covariate.

${ }^{21}$ Osler et al. (2003) consider the over-all mortality rate before age 50 as a function of birth weight, parental social class and IQ at age 12. All three have a significant effect. Including IQ at age 12 to the specification does not affect the birth weight coefficients. This is consistent with our findings.
} 
the evidence in the literature. Batty et al. (2009) report a negative effect of IQ at age 18 on the coronary heart disease (CHD) mortality rate up to age 52, across the full IQ range, and controlling for parental social class and birth year. The estimated effect size is as large as $30 \%$ for a one-standard deviation change in the cognitive measure. This is substantially larger than our estimated effect (about $8 \%$ for a one-standard deviation change). Perhaps CHD mortality at middle ages is more responsive to ability than CV mortality at high ages, or perhaps IQ at age 18 is confounded by events in the age interval 11-17. In the context of our paper, a more interesting explanation for the difference is that Batty et al. (2009) do not control for confounding by birth weight. After all, as we have seen, a higher birth weight leads to lower CV mortality as well as higher ability. More in general, studies on the effect of cognitive functioning in childhood on late-life health and cause-specific mortality typically assume tacitly that ability is exogenous while excluding conditions around birth as covariates (see the literature overview in Batty, Deary and Gottfredson, 2007). By implication, they may over-estimate the beneficial effect of ability. Osler et al. (2003) find that omitting birth weight from a PH model for over-all mortality until age 50 as a function of IQ at age 12 and parental social class does not affect the IQ coefficient. However, they do not control for transitory economic conditions around birth. In our own CV mortality analysis, if we omit birth weight and the business cycle from our specification with ability as explanatory variable then the coefficient of ability goes from 0.039 to -0.045 , and if we omit parental social class as well then the coefficient becomes -0.048 (standard error always 0.015 ). By ignoring confounding by earlylife conditions, the estimated size of the effect of a change in ability on the CV mortality rate thus increases. We conclude from this that studies of the effect of ability early in life on health later in life should try to control for confounding by early-life conditions.

Absence of an indirect pathway does not rule out that high ability mitigates (or enhances) the long-run effects of early-life conditions. To study this, we estimate the CV mortality models with interactions between early-life conditions on the one hand and ability on the other. The results unambiguously show that these interactions are not significantly different from zero. The final columns of Table 5 give the results for the parsimonious specification. The marginal ability effect and the other coefficients are not affected by the inclusion of ability interaction effects. We conclude that the long-run effects of early-life conditions are not influenced by ability. ${ }^{22}$

\footnotetext{
${ }^{22}$ Here and below we do not report SPL estimates. The subsamples that can be used are small since they require multi-sibling observation of ability and level of education (requiring
} 


\subsection{The level of education}

In this subsection we consider education as an intermediary in-between early-life conditions and ability on the one hand, and CV mortality on the other hand. We examine to what extent long-run effects run through education and to what extent education mitigates or reinforces adverse early-life conditions. The empirical approach is analogous to that used for ability in the previous subsections.

Table 6 reports regression estimates for the highest attained individual level of education as a function of the parsimonious set of covariates. In this set we include ability because a priori it seems an important determinant of the level of education. However, as we have seen, it is partly determined by early-life conditions, and as such its effect may reflect effects of early-life conditions. We therefore also estimate a more reduced-form specification in which ability is omitted (final columns). Notice that this results in a larger sample size (but this does not affect the results).

We conclude that birth weight and the business cycle at birth do not have an influence on the level of education. Although the signs of the effects are in line with a beneficial education effect of favorable conditions around birth, the coefficients are insignificant and small. This result applies whether we control for ability or not. Hence, there is no direct and no indirect effect.

Not surprisingly, ability has a strong effect on education. Putting this together with the findings accumulated above, we conclude that one component of ability depends on economic and biological early-life conditions and a different component affects the attained level of education. This confirms that early-life cognitive ability is a composite measure consisting of heterogeneous components. ${ }^{23}$ An additional implication of the above findings is that the cycle at birth and birth weight do not confound the effect of ability on education, since these two indicators of early-life conditions do not affect education in the first place.

Next to ability, education is primarily determined by social class at birth. The latter is strongly related to (and will often equal) social class at schoolgoing ages. ${ }^{24}$ In an era where access to higher education was easier if parents were

survival up to 1970; see Subsection 5.3) as well as residence in the Uppsala school district and a sufficient number of CV deaths. Moreover, with a small sample, estimates of interaction effects may be sensitive to the assumed functional form of the dependence of CV mortality on early-life conditions since ability also depends on these conditions.

${ }^{23}$ If the data would contain childhood behavioral outcomes then we could investigate the role of ability more deeply, by using a random-effects approach along the lines of Carneiro, Hansen and Heckman (2003). Specifically, we could allow ability to depend on latent factors capturing different components which also affect childhood behavioral outcomes.

${ }^{24} \mathrm{In}$ this sense, the result is consistent with the findings in the literature of family income and 
Table 6: OLS estimates of regression models for the highest attained level of education

\begin{tabular}{|c|c|c|c|c|c|c|}
\hline variable & est. & $\begin{array}{r}\text { arsimoniou } \\
\text { (st.error) }\end{array}$ & $\mathrm{t}$ & $\begin{array}{l}\text { id., } \\
\text { est. }\end{array}$ & $\begin{array}{l}\text { vithout a } \\
\text { (st.error }\end{array}$ & \\
\hline $\log ($ birth year-1914) & 0.047 & $(0.026)$ & 1.8 & 0.020 & $(0.023)$ & 0.9 \\
\hline business cycle at birth & 0.21 & $(0.31)$ & 0.7 & 0.25 & $(0.27)$ & 0.9 \\
\hline $\log$ (birth weight) & 0.060 & $(0.12)$ & 0.5 & 0.14 & $(0.10)$ & 1.3 \\
\hline cycle at birth $* \log$ (birth weight) & -2.30 & $(1.90)$ & 1.2 & -1.12 & $(1.62)$ & 0.7 \\
\hline social class at birth (inverse scale) & -0.13 & $(0.011)$ & 12.0 & -0.18 & $(0.0090)$ & 19.3 \\
\hline ability score & 0.12 & $(0.0090)$ & 12.9 & & & \\
\hline sample size & & 3957 & & & 5836 & \\
\hline
\end{tabular}

Note: explanatory variables that are interacted are measured in deviation from their mean value. The columns denoted by "t" give the t-values. Constant terms not reported.

wealthy, it is plausible that social class had a large influence on education (see e.g. Jonsson, 1991, for Swedish historical evidence on the importance of class background on education). In eras where access is universal, this effect may be smaller, while the effect of other early-life conditions might be larger. Indeed, Oreopoulos et al. (2008), examining Canadian birth cohorts 1978-1985, find that birth weight affects whether a certain level of education has been achieved at age 17. This carries over to their sibling fixed effect analysis.

Our findings on the determinants of education also hold if we use the extended set of covariates. The only additional covariate that has a significant effect on education is whether one is born in the city (positive effect). The results are also confirmed by Fixed Effects analyses of the level of education, allowing for sibling fixed effects. In those analyses, ability is a significant determinant of education but the early-life indicators are not.

We now turn to CV mortality analyses. Recall that the level of education is

educational achievement (see Duncan, 2006, for a survey). In this literature, interventions are analyzed where family income is increased over a substantial range of (early) childhood years. 
Table 7: Cox-PL parameter estimates of PH Models for the individual CV mortality rate with the level of education as a covariate

\begin{tabular}{|c|c|c|c|c|c|c|}
\hline variable & \multicolumn{3}{|c|}{ without ability } & & $\begin{array}{l}\text { th ability } \\
\text { (st.error) }\end{array}$ & $\mathrm{t}$ \\
\hline $\log ($ birth year-1914) & -0.24 & $(0.041)$ & 5.7 & -0.22 & $(0.048)$ & 4.5 \\
\hline business cycle at birth & -1.41 & $(0.45)$ & 3.1 & -1.65 & $(0.54)$ & 3.1 \\
\hline $\log$ (birth weight) & -0.46 & $(0.17)$ & 2.7 & -0.57 & $(0.20)$ & 2.8 \\
\hline cycle at birth $* \log$ (birth weight) & 6.55 & $(2.39)$ & 2.7 & 7.12 & $(2.76)$ & 2.6 \\
\hline education & -0.11 & $(0.025)$ & 4.4 & -0.073 & $(0.030)$ & 2.4 \\
\hline education $*$ cycle at birth & 0.098 & $(0.36)$ & 0.3 & -0.16 & $(0.43)$ & 0.4 \\
\hline education $* \log$ (birth weight) & -0.12 & $(0.16)$ & 0.7 & -0.024 & $(0.19)$ & 0.1 \\
\hline social class at birth (inverse scale) & 0.048 & $(0.016)$ & 3.0 & 0.050 & $(0.019)$ & 2.6 \\
\hline ability score & & & & -0.024 & $(0.016)$ & 1.5 \\
\hline sample size & & 5828 & & & 3950 & \\
\hline log partial likelihood & & -10836.7 & & & -7327.7 & \\
\hline
\end{tabular}

Note: explanatory variables that are interacted are measured in deviation from their mean value. The columns denoted by " $\mathrm{t}$ " give the $\mathrm{t}$-values.

observed in 1970. Specifically, it is observed in the 1970 census which took place on November 1, 1970. Hence, we restrict the mortality analyses to those alive on that day. Partial likelihood estimation of the $\mathrm{PH}$ model rules out dynamic selection on unobservables before this date, so that the ensuing covariate effects may be attenuated.

Since we found that education is not determined by our early-life indicators, we already know that there is no indirect effect from those indicators to CV mortality. Hence we focus on interaction effects of education and the indicators, to examine if education influences the detrimental effects of adverse conditions early in life. Table 7 presents the results. Clearly, there are no such interactions. Notice that education itself is highly significant. ${ }^{25}$ Recall that the association of

\footnotetext{
${ }^{25}$ Many studies have reported significant effects of education on over-all mortality (see the overview in Cutler and Lleras-Muney, 2006). However, Clark and Royer (2013), using more
} 
education and CV mortality is not confounded by our two indicators of early-life conditions.

As a covariate, education reduces the CV mortality effect of ability that we found in the previous subsection, making it insignificant. This, together with the results that ability affects education and ability affects $\mathrm{CV}$ mortality if education is omitted, implies that ability has an indirect effect on CV mortality by way of the attained level of education and that it does not have additional effects on CV mortality. Notice that this indirect pathway from ability to education and onwards to CV mortality is not related to early-life conditions.

The study by Batty et al. (2009) discussed in the previous subsection follows post-1950 Swedish birth cohorts until 2002. Interestingly, they find that the inclusion of education in the CHD mortality rate substantially attenuates the association between ability at age 18 and CHD mortality. This suggests that our finding is not completely driven by the institutional setting of the pre-World War II educational system in Sweden.

As in all mortality analyses in the paper, the calendar time trend variable and the parental social class at birth are the covariates with the largest effects on the CV mortality rate. This is of course not surprising. The trend variable captures secular changes in society over time. Parental social class reflects family-specific behavioral habits, lifestyle, and the long-run wealth level throughout life.

The data also contain observations of the level of education attained by 1960 as reported in the census from November 1, 1960. Unfortunately, the categorization of the low education levels in less precise than in 1970. However, we may use the observations to plug in values in case the level in 1970 was not observed. This increases the sample size with about $5 \%$. The ensuing estimation results are essentially the same as those reported in this subsection. The latter also applies if we proxy ability with the average test score across subject fields.

\section{Conclusion}

In this paper we have analyzed long-run effects of the business cycle at birth and birth weight on cardiovascular mortality at high ages. A recession at birth and a lower birth weight each lead to higher CV mortality. We find that the association between birth weight and CV mortality later in life is significantly stronger if the individual is born in a recession. Birth weight is a more powerful predictor of CV mortality if the individual is born in a recession than if he is born during an

recent birth cohorts than our study, only find a small causal effect. 
economic boom. Equivalently, among individuals with a lower birth weight it is more informative whether the business cycle at birth was favorable or not.

These results can be taken at face value and can be used to identify individuals at high risk for CV mortality. We also aim to go beyond that and to identify causal effects. This is facilitated by our finding that the birth weight distribution does not vary over the business cycle. By exploiting the presence of siblings in the data we find that the long-run effects of birth weight are mostly family-specific. We conclude that birth weight as a covariate mostly captures background variation due to unobserved biological and genetic characteristics, provided that other steady socio-economic and lifestyle family characteristics are properly accounted for by our social class indicators. Along these lines, the interaction effect of business cycle and birth weight translates into an interaction effect of $(i)$ economic conditions at birth and (ii) the inherited biological and genetic setting.

The long-run effects of these two aspects of early-life conditions on CV mortality do not run through cognitive ability or education. Instead, they reflect a direct long-run biological causal effect. Economic conditions around birth (influencing nutrition and/or stress around birth) and the inherited genetic and biological family background appear to program the body of the individual in a way that affects CV mortality at high ages. These direct long-run effects are not mitigated by a high cognitive ability and/or a high education. For example, a high level of education does not reduce the size of the association between birth weight and CV mortality.

A high birth weight and favorable economic conditions at birth have significantly positive effects on cognitive ability. However, these effects are small, and they do not carry over towards the level of education or CV mortality. The overall long-run effect of early-life conditions is therefore mostly a direct biological effect.

In general, we identify two causal pathways leading up to CV mortality at high ages. The first pathway is the aforementioned direct biological effect that starts with the economic (nutritional/stress) conditions at birth and with the inherited genetic and biological family background. The second pathway runs from cognitive ability to the highest acquired level of education on to CV mortality. These two pathways are separate from each other, and they do not act as complements or substitutes.

We repeat some cautionary remarks. First, if there are family lifestyle characteristics that affect birth weight and that are not related to social class then the estimated effects of birth weight may include effects of such characteristics. Secondly, aspects of early-life conditions may exist that are not related to any of the 
indicators we control for and that may affect CV mortality in a different way than along the direct long-run biological effect. Thirdly, the inference on the effect of education suffers from an absence of instrumental variation. At the same time, in general, the role of education is necessarily affected by institutional constraints. With easy access to higher education, the highest achieved level effect may be found to depend on early-life conditions as well. Whether this has implications for CV mortality cannot be studied until recent birth cohorts reach high ages.

The paper makes some methodological contributions. First, we find that earlylife conditions (as captured by birth weight and the cycle at birth) are confounders in the relation between cognitive ability early in life and CV mortality late in life. The literature has ignored this, which may have frequently led to an overestimation of the effect of ability on CV mortality. Secondly, our paper is the first to use Stratified Partial Likelihood as a fixed-effect estimation method in the study of long-run effects on mortality. This method controls for a number of selectivity problems that have haunted the literature, notably for selective fertility in adverse times.

The paper has not examined intermediate outcomes during adult life, such as marital status, income, and social mobility. In principle, such an examination would allow for a more detailed investigation of causal pathways. For example, Van den Berg and Gupta (2011) consider the role of marriage and find that among women it worsens the mortality effects of adverse conditions around birth, especially in childbearing ages. However, in general, the range of possible model specifications for an outcome as a function of previous outcomes increases exponentially with the number of intermediate outcomes. Such an endeavor is beyond the scope of this paper. Moreover, the detection of interaction effects becomes susceptible to misspecification errors, since intermediate outcomes may pick up non-linear effects of early-life conditions. Nevertheless, we see it as an important topic for further research.

We end this section with some additional remarks about the relevance for more recent birth cohorts. The living conditions in Sweden around 1925 were good in comparison to most other countries at the time, and in comparison to many developing countries today. Nevertheless, conditions in Sweden around 80 years ago were different from current conditions. Furthermore, in terms of income loss, pre-1930 recessions may have been more intrusive than modern recessions. In this respect it is important to make 4 points. First of all, notice that that we aim to uncover causal mechanisms whose existence goes beyond the particular era from which data are used to identify them. We use pre-1930 cycles as sources of exogenous variation to identify effects of which the existence does not depend on 
whether those particular sources still abound. Secondly, recent biological research has shown that it is not only fetal malnourishment as such that leads to long-run effects on CVD outcomes, but, more generally, that discrepancies between earlylife conditions in utero and shortly after birth on the one hand, and later lifestyle on the other hand, lead to long-run effects on CVD outcomes (see e.g. Kuzawa and Quinn, 2009, Gluckman and Hanson, 2004, Mogren et al., 2001, Holemans, Caluwaerts and Van Assche, 2002, and Fogel, 1997). In modern societies, individuals born in low-income households who have high nutritional intakes later in life may be particularly at risk for adverse CVD outcomes at high ages. Thirdly, inequality has risen sharply in Sweden over the past 10 years. The average replacement rate (i.e., the ratio of unemployment benefits to pre-unemployment earnings) is as low as $50 \%$ which is below the OECD median value. Fourthly, recall that adverse early-life conditions involve stress, and modern recessions may involve a substantial amount of stress. Many individuals may fear job loss during recessions, and the mean time out of work following job loss is much higher than in the past. From a policy point of view, it seems therefore recommendable to secure a sufficient income level to poor pregnant women and poor women with infants. This may involve the provision of cash transfers to such women.

For developing countries that could be regarded as similar to or worse off than Sweden in the birth year period of the present paper, the existing literature has focused on inequalities in infant and child mortality by household socioeconomic status, since there are typically no long run data registers (see Sastry, 2004). In this sense, our paper aims to complement these studies, by studying long-run mortality effects. 


\section{References}

Abu-Saad, K. and D. Fraser (2010), Maternal nutrition and birth outcomes, Epidemiological Reviews 32, 5-25.

Ahlström, K.G. (2011), The origin of special education in Sweden, Education Inquiry 2, 179-192.

Almond, D., K. Chay and D. Lee (2005), The costs of low birth weight, Quarterly Journal of Economics 120, 1031-1083.

Almond, D. and J. Currie (2011), Killing me softly: The fetal origins hypothesis, Journal of Economic Perspectives 25, 153-172.

Antonow-Schlorke, I., M. Schwab, L.A. Cox, C. Li, K. Stuchlik, O.W. Witte et al. (2011), Vulnerability of the fetal primate brain to moderate reduction in maternal global nutrient availability, Proceedings of the National Academy of Sciences of the USA 108, 3011-3016.

Barker, D. (2007), The origins of the developmental origins theory, Journal of Internal Medicine 261, 412-417.

Basso, O. (2008), Birth weight is forever, Epidemiology 19, 204-205.

Batty, G.D., I.J. Deary, and L.S. Gottfredson (2007), Premorbid (early life) IQ and later mortality risk: systematic review, Annals of Epidemiology 17, 278-288.

Batty, G.D., K.M. Wennerstad, G. Davey Smith, D. Gunnell, I.J. Deary, P. Tynelius et al. (2009), IQ in early adulthood and mortality by middle age, Epidemiology 20, $100-109$.

Bengtsson, T. and M. Lindström (2000), Childhood misery and disease in later life: The effects on mortality in old age of hazards experienced in early life, southern Sweden, 1760-1894, Population Studies 54, 263-277.

Bengtsson, T. and M. Lindström (2003), Airborne infectious diseases during infancy and mortality in later life in southern Sweden, 1766-1894, International Journal of Epidemiology 32, 286-294.

Ben-Shlomo, Y. (2001), Commentary: Are birthweight and cardiovascular associations due to fetal programming?, International Journal of Epidemiology 30, 862-863.

Blakely, T. (2002), Commentary: estimating direct and indirect effects - fallible in theory, but in the real world?, International Journal of Epidemiology 31:166167.

Brown, R. (2011), The 1918 U.S. influenza pandemic as a natural experiment, revisited, Working paper, Duke University.

Carneiro, P., K.T. Hansen and J.J. Heckman (2003), Estimating distributions of treatment effects with an application to the returns to schooling and measurement of the effects of uncertainty on college choice, International Economic Review 44, 361-422. 
Clark, D. and H. Royer (2013), The effect of education on adult health and mortality: evidence from Britain, American Economic Review, forthcoming.

Currie, J. and N. Cole (1993), Welfare and child health: the link between AFDC participation and birth weight, American Economic Review 83, 971-985.

Currie, J. and E. Moretti (2007), Biology as destiny? Short- and long-run determinants of intergenerational transmission of birth weight, Journal of Labor Economics 25, 231-263.

Cutler, D.M. and A. Lleras-Muney (2006), Education and health: evaluating theories and evidence, Working paper, NBER, Cambridge MA.

Dehejia, R., and A. Lleras-Muney (2004), Booms, busts and babies health, Quarterly Journal of Economics 119, 1091-1130.

Doblhammer, G. (2004), The Late Life Legacy of Very Early Life, Springer, Berlin.

Duncan, G.J. (2006), Income and Child Well-Being, Geary Lecture Series 34, ESRI, Dublin.

Edvinsson, R. (2005), Growth, Accumulation, and Crisis: With New Macroeconomic Data for Sweden 1800-2000, Almqvist \& Wiksell International, Stockholm.

Eriksson, J.G. (2007), Epidemiology, genes and the environment: lessons learned from the Helsinki Birth Cohort Study, Journal of Internal Medicine 261, 418-425.

Eriksson, J.G., E. Kajantie, C. Osmond, K. Thornburg and D.J.P. Barker (2010), Boys live dangerously in the womb, American Journal of Human Biology 22, 330-335.

Fellman, J. and A.W. Eriksson (2006), Stillbirth rates in singletons, twins and triplets in Sweden, 1869 to 2001, Twin Research and Human Genetics 9, 260-265.

Fletcher, J.M. (2012), Why have tobacco control policies stalled? Using genetic moderation to examine policy impacts, PLOS ONE 7, e50576.

Fogel, R.W. (1997), New findings on secular trends in nutrition and mortality: some implications for population theory, in: M.R. Rosenzweig and O. Stark (eds.), Handbook of Population and Family Economics, North-Holland, Amsterdam.

Fredriksson, P. and B. Öckert (2005), Is early learning really more productive? The effect of school starting age on school and labor market performance, Working paper, IFAU Uppsala.

Gluckman, P.D. and M.A. Hanson (2004), Living with the past: evolution, development, and patterns of disease, Science 305, 1733-1736.

Gluckman, P.D., M.A. Hanson and C. Pinal (2005), The developmental origins of adult disease, Maternal and Child Nutrition 1, 130-141.

Goodman, A., M. Gisselmann and I. Koupil (2010), Birth characteristics and early-life social characteristics predict unequal educational outcomes across the lifecourse and across generations, Longitudinal and Life Course Studies 1, 315-316. 
Grytten, O.H. (2006), Economic policy and labour markets in Nordic countries during the great depression of the 1930s, Working paper, Norwegian School of Economics and Business Administration.

Hart, C.L., M.D. Taylor, G. Davey Smith, L.J. Whalley, J.M. Starr, D.J. Hole et al. (2004), Childhood IQ and cardiovascular disease in adulthood: prospective observational study linking the Scottish Mental Survey 1932 and the Midspan studies, Social Science and Medicine 59, 2131-2138.

Heijmans, B.T., E.W. Tobi, A.D. Stein, H. Putter, G.J. Blauw, E.S. Susser et al. (2008), Persistent epigenetic differences associated with prenatal exposure to famine in humans, Proceedings of the National Academy of Sciences of the USA 105, 1704617049 .

Holemans, K., S. Caluwaerts, and F.A. Van Assche (2002), Unravelling the fetal origins hypothesis, Lancet 360, 2073.

Huxley, R., C.G. Owen, P.H. Wincup, D.G. Cook, J. Rich-Edwards, G. Davey Smith and R. Collins (2007), Is birth weight a risk factor for ischemic heart disease in later life?, American Journal of Clinical Nutrition 85, 1244-1250.

Isacson, M. and L. Magnusson (1996), Arbetarstaden Uppsala, Gidlunds förlag, Möklinta. Järvelin, M.R., U. Sovio, V. King, L. Lauren, B. Xu, M.I. McCarthy, A.L. Hartikainen, J. Laitinen, P. Zitting, P. Rantakallio and P. Elliott (2004), Early life factors and blood pressure at age 31 years in the 1966 Northern Finland Birth Cohort, Hypertension 44, 838-846.

Johansson, M. (2004), En studie av synen på kvinnor och högre utbildning. I samband med läroverksreformen 1927, Working paper, Linköping University.

Jonsson, J. (1991), School reforms, educational expansion, and educational attainment: trends toward equality in Sweden, Working paper, Stockholm University.

Jonung, L. and T. Hagberg (2005a), 1990-talskrisen - hur svår war den?, Ekonomisk Debatt 33.8, 30-45.

Jonung, L. and T. Hagberg (2005b), How costly was the crisis of the 1990s? A comparative analysis of the deepest crises in Finland and Sweden over the last 130 years, Working paper, European Commission.

Kåreholt, I. (2001), The long shadow of socioeconomic conditions in childhood: do they affect class inequalities in mortality?, in: J.O. Jonsson and C. Mills, eds., Cradle to Grave: Life-course Change in Modern Sweden, Sociology Press, Durham.

Kaestner, R. and W.C. Lee (2005), The effect of welfare reform on prenatal care and birth weight, Health Economics 14, 497-511.

Kalbfleisch, J.D. and R.L. Prentice (1980), The Statistical Analysis of Failure Time Data, Wiley, New York. 
Kaufman, J.S., R.F. MacLehose and S. Kaufman (2004), A further critique of the analytic strategy of adjusting for covariates to identify biologic mediation, Epidemiological Perspectives and Innovations 1:4.

Kolk, M. (2009), Deliberate birth spacing in pre-transitional Sweden, Working paper, Stockholm University.

Kramer, M.S. (1987), Determinants of low birth weight: methodological assessment and meta-analysis, Bulletin of the World Health Organization 65, 663-737.

Kuh, D. and Y. Ben-Shlomo (2004), A Life Course Approach to Chronic Disease Epidemiology, Oxford University Press, Oxford.

Kungliga Medicinalstyrelsen (1918-1931), Allmän Hälso- och Sjukvård År 1915, Ar 1916,..., Ar 1929, Norstedt, Stockholm.

Kuzawa, C.W. (2008), The developmental origins of adult health: intergenerational inertia in adaptation and disease, in: W. Trevathan et al. (eds.), Evolution and Health, Oxford University Press, Oxford.

Kuzawa, C.W. and E.A. Quinn (2009), Developmental origins of adult function and health: evolutionary hypotheses, Annual Review of Anthropology 38, 131-147.

Lange, T. and J.V. Hansen (2011), Direct and indirect effects in a survival context, Epidemiology 22, 575-581.

Lawlor, D.A. (2008), The developmental origins of health and disease: where do we go from here?, Epidemiology 19, 206-208.

Lawlor, D.A., Y. Ben-Shlomo and D.A. Leon (2004), Pre-adult influences on cardiovascular disease, in: D. Kuh and Y. Ben-Shlomo (eds.), A Life Course Approach to Chronic Disease Epidemiology, Oxford University Press, Oxford.

Leon, D.A., H.O. Lithell, D. Vågerö, I. Koupilová, R. Mohsen, L. Berglund et al. (1998), Reduced fetal growth rate and increased risk of death from ischaemic heart disease: cohort study of 15000 Swedish men and women born 191529, British Medical Journal $317,241-245$.

Lobell, H., L. Schön and O. Krantz (2007), Observations from the new Swedish Historical National Accounts, Working paper, Lund University.

Low, B.S. (2001), Why Sex Matters: A Darwinian Look at Human Behavior, Princeton University Press, Princeton NJ.

Lumey L.H., A.D. Stein, and E. Susser (2011), Prenatal famine and adult health, Annual Review of Public Health 32, 24.1-24.26.

Magnus, P., L.S. Bakketeig and R. Skjærven (1993), Correlations of birth weight and gestational age across generations, Annals of Human Biology 20, 231-238.

Magnus, P., H.K. Gjessing, A. Skrondal, and R. Skjærven (2001), Paternal contribution to birth weight, Journal of Epidemiology and Community Health 55, 873-877. 
Margerison Zilko, C.E. (2010), Economic contraction and birth outcomes: an integrative review, Human Reproduction Update 16, 445-458.

Matte, T.D., M. Bresnahan, M.D. Begg, and E. Susser (2001), Influence of variation in birth weight within normal range and within sibships on IQ at age 7 years: cohort study, British Medical Journal 323, 310.

Mitchell, B.R. (2003), International Historical Statistics: Europe, 1750-2000, Palgrave Macmillan, New York.

Modin, B. (2002), Setting the Scene for Life: Longitudinal Studies of Early Social Disadvantage and Later Life Chances, Centre for Health Equity Studies, Stockholm.

Mogren, I., U. Högberg, B. Stegmayr, B. Lindahl, and H. Stenlund (2001), Fetal exposure, heredity and risk indicators for cardiovascular disease in a Swedish welfare cohort, International Journal of Epidemiology 30, 853-862.

National Central Bureau of Statistics (1915-1931), Kommunernas Statistiska Uppgifter, 1914-1930, National Central Bureau of Statistics, Stockholm.

National Central Bureau of Statistics (1969), Historical Statistics of Sweden, Part 1. Population, Second edition, 1720-1967, National Central Bureau of Statistics, Stockholm.

Oreopoulos, P., M. Stabile, R. Walld and L.L. Roos (2008), Short-, medium-, and longterm consequences of poor infant health, Journal of Human Resources 43, 88-138.

Osler, M., A.M.N. Andersen, P. Due, R. Lund, M.T. Damsgaard and B.E. Holstein (2003), Socioeconomic position in early life, birth weight, childhood cognitive function, and adult mortality. A longitudinal study of Danish men born in 1953, Journal of Epidemiology and Community Health 57, 681-686.

Poulter, N.R., C.L. Chang, A.J. MacGregor, H. Snieder and T.D. Spector (1999), Association between birth weight and adult blood pressure in twins: historical cohort study, British Medical Journal 319, 1330-1333.

Rajaleid, K., O. Manor and I. Koupil (2008), Does the strength of the association between foetal growth rate and ischaemic heart disease mortality differ by social circumstances in early or later life?, Journal of Epidemiology and Community Health 62, 5:e6.

Rasmussen, K.M. (2001), The "fetal origins" hypothesis: challenges and opportunities for maternal and child nutrition, Annual Review of Nutrition 21, 73-95.

Richards, M., R. Hardy, D. Kuh and M. Wadsworth (2001), Birth weight and cognitive functioning in the British 1946 birth cohort: longitudinal population based study, British Medical Journal 332, 199-203.

Ridder, G. and I. Tunalı (1999), Stratified partial likelihood estimation, Journal of Econometrics 92, 193-232. 
Sastry, N. (2004), Trends in socioeconomic inequalities in mortality in developing countries: the case of child survival in Sao Paulo, Brazil, Demography 41, 443-464.

Saugstad, L.F. (1999), Optimality of the birth population reduces learning and behaviour disorders and sudden infant death after the first month, Acta Paediatrica Supplement 429, 9-28.

Shenkin, S.D., J.M. Starr and I.J. Deary (2004), Birth weight and cognitive ability in childhood: a systematic review, Psychological Bulletin 130, 989-1013.

Skjærven, R. (2011), Generational data: the Medical Birth Registry of Norway and the Norwegian Mother and Child Study, Working paper, University of Bergen.

Socialstyrelsen (1915-1929), Sociala Meddelanden 1915 Häften 1-6, 1915 Häften 7-12, 1916 Häften 1-6,...,1929 Häften 7-12, Norstedt, Stockholm.

Stams, G.J.J.M., F. Juffer and M.H. van IJzendoorn (2002). Maternal sensitivity, infant attachment, and temperament predict adjustment in middle childhood: The case of adopted children and their biologically unrelated parents, Developmental Psychology $38,806-821$.

Statistics Sweden (1999), Population development in Sweden in a 250-year perspective, Working paper, Statistics Sweden.

Stein, A.D., M. Wang, A. DiGirolamo, R. Grajeda, U. Ramakrishnan, M. RamirezZea et al. (2008), Nutritional supplementation in early childhood, schooling, and intellectual functioning in adulthood: a prospective study in Guatemala, Archives of Pediatrics and Adolescent Medicine 162, 612-618.

Sundin, J. and S. Willner (2007), Social Change and Health in Sweden: 250 Years of Politics and Practice, Swedish National Institute of Public Health, Östersund.

Thorp, W.L. and H.E. Thorp (1926), The Annals of Sweden, in: W.L. Thorp (ed.), Business Annals, NBER, Cambridge.

Ullenhag, K. (1984), Industriell Utveckling och Demokratisering, 1862-1921, Almqvist \& Wiksell, Uppsala.

Van den Berg, G.J. (2001), Duration models: specification, identification, and multiple durations, in: J.J. Heckman and E. Leamer (eds.), Handbook of Econometrics, Volume V, North-Holland, Amsterdam.

Van den Berg, G.J., M. Lindeboom and F. Portrait (2006), Economic conditions early in life and individual mortality, American Economic Review 96, 290-302.

Van den Berg, G.J. and M. Lindeboom (2007), Birth is the messenger of death but policy may help to postpone the bad news. New evidence on the importance of conditions early in life for health and mortality at advanced ages, Netspar Panel Paper 4, Tilburg University. 
Van den Berg, G.J., M. Lindeboom and M. López (2009), Inequality in individual mortality and economic conditions earlier in life, Social Science and Medicine 69, 1360-1367.

Van den Berg, G.J., Lundborg, P., Nystedt, P., and Rooth, D. (2010), Critical periods during childhood and adolescence: a study of adult height among immigrant siblings, Working paper, IZA Bonn.

Van den Berg, G.J. and S. Gupta (2011), The role of marriage in the causal pathway from economic conditions early in life to mortality, Working paper, IFAU Uppsala.

Van den Berg, G.J., G. Doblhammer and K. Christensen (2011), Being born under adverse economic conditions leads to a higher cardiovascular mortality rate later in life - evidence based on individuals born at different stages of the business cycle, Demography 48, 507-530.

Westrin, T. (1920), Nordisk Familjebok, 2nd Edition, Volume 30, Nordisk familjeboks förlags aktiebolag, Stockholm.

Wienke, A., K. Christensen, A. Skytthe and A.I. Yashin (2002), Genetic analysis of cause of death in a mixture model of bivariate lifetime data, Statistical Modelling 2, $1-14$. 


\section{Appendix: miscellaneous estimation results}

Table 8: Fixed Effects panel data model estimates for the log individual birth weight

\begin{tabular}{|c|c|c|c|c|c|c|}
\hline variable & \multicolumn{2}{|c|}{ all covariates } & $\mathrm{t}$ & $\begin{array}{l}\text { pa } \\
\text { est. }\end{array}$ & parsimonious & $\mathrm{t}$ \\
\hline $\log ($ birth year-1914) & 0.0043 & $(0.026)$ & 0.2 & & & \\
\hline business cycle at birth & 0.056 & $(0.10)$ & 0.5 & 0.061 & $(0.070)$ & 0.9 \\
\hline birth in city & 0.0046 & $(0.0044)$ & 1.0 & & & \\
\hline social class at birth (inverse scale) & -0.017 & $(0.019)$ & 0.9 & & & \\
\hline mother's age, at birth & 0.0038 & $(0.0043)$ & 0.9 & 0.0055 & $(0.0012)$ & 4.6 \\
\hline mother married, at birth & 0.055 & $(0.0017)$ & 3.3 & & & \\
\hline birth in fall & 0.018 & $(0.012)$ & 1.5 & & & \\
\hline birth in winter & 0.0080 & $(0.012)$ & 0.7 & & & \\
\hline birth in spring & 0.0050 & $(0.012)$ & 0.4 & & & \\
\hline sample size (individuals) & & 2162 & & & 2162 & \\
\hline sample size (mothers) & & 933 & & & 933 & \\
\hline
\end{tabular}

Note: the fixed effect is mother-specific and hence is common across brothers. The columns denoted by "t" give the t-values. 
Table 9: Stratified Partial Likelihood estimates for the individual CV mortality rate

\begin{tabular}{|l|rll|}
\hline \hline & & & \\
variable & est. & (st.error) & $\mathrm{t}$ \\
\hline & & & \\
$\log$ (birth year-1914) & -0.19 & $(0.15)$ & 1.3 \\
business cycle at birth & -4.72 & $(1.79)$ & 2.6 \\
$\log$ (birth weight) & 0.98 & $(0.90)$ & 1.1 \\
cycle at birth $* \log$ (birth weight) & 18.1 & $(11.0)$ & 1.6 \\
\hline sample size (individuals) & & 1730 \\
sample size (mothers) & & 791 \\
\hline \hline
\end{tabular}

Note: the fixed effect is mother-specific and hence is common across brothers. The columns denoted by "t" give the t-values. 